\title{
Polyomic tools for an emerging livestock parasite, the rumen fluke Calicophoron daubneyi; identifying shifts in rumen functionality
}

Kathryn M. Huson, Russell M. Morphew*, Nathan R. Allen, Matthew J. Hegarty, Hillary J. Worgan, Susan E. Girdwood, Eleanor L. Jones, Helen C. Phillips, Martin Vickers, Martin Swain, Daniel Smith, Alison H. Kingston-Smith and Peter M. Brophy

\begin{abstract}
Background: Diseases caused by parasitic flatworms of rumen tissues (paramphistomosis) are a significant threat to global food security as a cause of morbidity and mortality in ruminant livestock in subtropical and tropical climates. Calicophoron daubneyi is currently the only paramphistome species commonly infecting ruminant livestock in temperate European climates. However, recorded incidences of $C$. daubneyi infection in European livestock have been increasing over the last decade. Whilst clinical paramphistomosis caused by adult worms has not been confirmed in Europe, fatalities have been attributed to severe haemorrhagic enteritis of the small intestine resulting from the migration of immature paramphistomes. Large numbers of mature adults can reside in the rumen, yet to date, the impact on rumen fermentation, and consequently on productivity and economic management of infected livestock, have not been resolved. Limited publicly available nucleotide and protein sequences for $C$. daubneyi underpin this lack of biological and economic understanding. Here we present for the first time a de novo assembled transcriptome, with functional annotations, for adult $C$. daubneyi, which provides a reference database for protein and nucleotide sequence identification to facilitate fundamental biology, anthelmintic, vaccine and diagnostics discoveries.

Results: This dataset identifies a number of genes potentially unique to C. daubneyi and, by comparison to an existing transcriptome for the related Paramphistomum cervi, identifies novel genes which may be unique to the paramphistome group of platyhelminthes. Additionally, we present the first coverage of the excretory/secretory and soluble somatic proteome profiles for adult $C$. daubneyi and identify the release of extracellular vesicles from adult $C$. daubneyi parasites during in vitro, ex-host culture. Finally, we have performed the first analysis of rumen fluke impacting upon rumen fermentation parameters using an in vitro gas production study resulting in a significant increase in propionate production.

Conclusions: The resulting data provide a discovery platform (transcriptome, proteomes, EV isolation pipeline and in vitro fermentation system) to further study C. daubneyi-host interaction. In addition, the acetate: propionate ratio has been demonstrated to decrease with rumen fluke infection suggesting that acidotic conditions in the rumen may occur.
\end{abstract}

Keywords: Calicophoron daubneyi, Transcriptome, Paramphistome, Proteomics, In vitro, Rumen fermentation

\footnotetext{
* Correspondence: rom@aber.ac.uk

Institute of Biological, Environmental \& Rural Sciences (IBERS), Aberystwyth

University, Penglais, Ceredigion, Aberystwyth SY23 3DA, UK
}

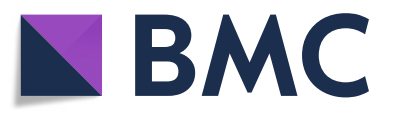

(C) The Author(s). 2018 Open Access This article is distributed under the terms of the Creative Commons Attribution 4.0 International License (http://creativecommons.org/licenses/by/4.0/), which permits unrestricted use, distribution, and reproduction in any medium, provided you give appropriate credit to the original author(s) and the source, provide a link to the Creative Commons license, and indicate if changes were made. The Creative Commons Public Domain Dedication waiver (http://creativecommons.org/publicdomain/zero/1.0/) applies to the data made available in this article, unless otherwise stated. 


\section{Background}

Parasitic helminth infections of livestock are a global threat to food security, sustainable agriculture and animal welfare. Significant financial losses are incurred by individual livestock producers and national/international agricultural economies annually due to the costs associated with animal morbidity, mortality, production loss and anthelmintic treatment $[1,2]$. Rumen fluke infection, or paramphistomosis, is a significant cause of morbidity and mortality in ruminant livestock in subtropical and tropical climates $[3,4]$ and is caused by several genera within the family Paramphistomidae. Paramphistomes have a complex indirect life-cycle, with a single intermediate snail host [5]. After ingestion by a ruminant host, metacercariae excyst in the duodenum and the immature parasites first move into the superficial mucosa of the intestine prior to migration up the alimentary tract to the rumen and reticulum. Mature paramphistomes appear generally well tolerated by host animals, with clinical disease frequently linked to immature rumen fluke causing significant damage to the mucosa of the duodenum $[6,7]$. Upon post-mortem examination haemorrhagic inflammation of the duodenum may also be observed [8].

To date in Europe, paramphistomosis has not been considered clinically significant [9] and historically infection was believed to be less common [10, 11]. However, incidences of rumen fluke infection have dramatically increased in temperate areas of western Europe over the last few decades and many prevalence studies have identified rumen fluke as a common parasitosis of ruminant livestock in temperate European climates [12]. For example, of 100 farms in Wales $61 \%$ were identified as positive for C. daubneyi infection in sheep or cattle [13]. The apparent substantial prevalence of an infection previously regarded as less common has led to an urgent interest in this comparatively poorly studied helminth parasite. Thus, increased understanding of the impact from rumen fluke infection on animal production is crucial. To this end, in vitro rumen fermentation is established as a key technology to provide biological understanding of rumen dynamics $[14,15]$. Ruminant animals rely on the microbial fermentation of feed and forage producing volatile fatty acids (VFAs) as their primary energy source [16]. Factors which impact on the profile of VFAs present in the rumen are known to impact on host nutrition with the ratios of the three major VFAs, produced via microbial fermentation in the rumen (acetate, propionate and butyrate) under a delicate balance.

Polyomics based technologies have allowed for significant expansion of our understanding of many aspects of parasitic helminth-host interaction biology in recent years [17-20]. To date, limited public available nucleotide and protein sequences for $C$. daubneyi hinder these functional genomic studies in this rapidly spreading livestock parasite. Thus, in the present study the molecular profile of the paramphistome $C$. daubneyi was revealed for the first time at both the transcript and the protein level via a functionally annotated de novo transcriptome and proteomic datasets for the excretory/ secretory (ES) products and the soluble somatic proteome. The datasets presented here reveal evidence of predicted novel protein sequences from the transcriptome and in the proteomes and for the first time reveal the potential presence of extracellular vesicles released from adult $C$. daubneyi during in vitro culture. A gas production trial provides evidence of rumen fluke metabolism to produce increased propionate as supported by $C$. daubneyi transcriptome data that identifies genes involved in the propionate production pathway.

\section{Methods}

\section{Species identification}

In total during the study, paramphistomes were collected from 65 infected cattle from 22 farms around Wales, and 1 farm in Shropshire, England. Infected animals ranged in age from 19 months to 15 years and were of varying breeds from both beef and dairy production systems, further highlighting the widespread presence of this parasite.

For each infected bovine from which parasites were collected, DNA was extracted from 3 specimens using a Qiagen DNeasy ${ }^{\circ}$ Blood and Tissue kit (Qiagen, Hilden, Germany) according to the manufacturer's directions. DNA elutions were then subject to PCR amplification using C. daubneyi specific primers developed previously [21] targeting an 885 bp region of the cytochrome $c$ oxidase subunit 1 ( $\operatorname{cox} 1)$ mitochondrial gene; Cd Cox1F (forward: 5'-TGG AGA GTT TGG CGT CTT TT-3') and Cd Cox1R (reverse: 5'-CCA TCT TCC ACC TCA TCT GG-3'). PCR products were visualised using gel electrophoresis on a 1\% TAE agarose gel viewed under UV. Positive amplification with appropriate product size was given to confirm species identification. For individual rumen fluke used for RNAseq analysis, total RNA was isolated using an RNeasy (Qiagen) blood and tissue procedure according to the manufacturer's instructions with $1 \mu \mathrm{g}$ of total RNA used to create cDNA libraries for PCR amplification to confirm the species ID, using $\operatorname{cox} 1$ as stated above, prior to sequencing.

\section{Transcriptomics: sample collection, RNA isolation and sequencing}

A natural rumen fluke parasite infection in a cow was identified immediately upon the opening of the rumen wall from a local abattoir (mid-Wales, UK). Individual parasite specimens from this single bovine host were rinsed briefly in sterile warm $\left(39^{\circ} \mathrm{C}\right)$ phosphate buffered saline (PBS) to remove large contaminating debris and 
immediately snap frozen in dry ice for transport. Samples were stored at $-80{ }^{\circ} \mathrm{C}$ until RNA isolation. Initially, frozen samples were homogenised using a Qiagen TissueLyser LT (Qiagen). Total RNA was then extracted from 3 individual parasites using a RNeasy mini kit (Qiagen) according to the manufacturer's directions, with an on-column DNase digestion step as directed in the RNeasy protocol. RNA quantity and integrity were measured using an Experion ${ }^{\text {Th }}$ Automated Electrophoresis Station and RNA HighSens analysis kit (Bio-Rad, UK) with a RIN number of $>8$ achieved for each sample. Total RNA $(1 \mu \mathrm{g})$ was then used to purify polyadenylated (poly A+) mRNA according to the TruSeq RNA Sample Preparation v2 LS Workflow (Illumina, Cambridge, UK) using TruSeq RNA Sample Prep Kit v2 (Illumina) to prepare a $100 \mathrm{bp}$ library for paired end sequencing. Each sample library was prepared with indexed adaptors as instructed in the Illumina workflow guide. Sequencing was performed on an Illumina HiSeq2500 platform according to standard protocols (Illumina).

\section{De novo assembly and bioinformatics}

The raw Illumina data was demultiplexed and converted to sample fastq files using Illumina bcl2fastq software (version 1.8.3). Read quality was assessed using FastQC (http://www.bioinformatics.babraham.ac.uk/projects/fastqc/). Three quality control steps were carried out on the reads using Trimmomatic (v0.32 2) [22]; Truseq adaptor sequences were removed via a 13 base crop of the $5^{\prime}$ end of the reads was carried out to resolve base bias identified by FastQC and the 3' end of the reads was cropped when the mean quality in a 4-base sliding window fell below a phred Q score of 20. Reads were assembled using Trinity (version date 2013-02-25) [23]. The resulting assembly file was functionally annotated using the Trinotate pipeline (V2.0) (https://trinotate. github.io/) and expression values for each contig, expressed as FPKM, were calculated using RSEM v1.2.25 [24]. Following RSEM analysis any unmapped reads (with an FPKM value of 0 ) were removed from further analyses. To visualise the gene ontology (GO) data for each contig the transcript ID and GO column data was extracted from the Trinotate output file and then loaded into Blast2 $\mathrm{GO}^{\circ}$ (V3.2) for visualisation. The top 50 expressed gene components identified by FPKM value were obtained by extracting the BLASTx UniProt identifier annotated to the longest isoform of each gene component ID and then uploading this to the UniProt mapping application (uniprot.org/mapping, accessed 03/12/2015) to obtain descriptive data on the protein matches, protein family, organism ID and associated GOslim information for each. For the top 50 expressed gene components identified by FPKM values which lacked any annotation, the longest isoform sequences for each was extracted from the assembly file and subjected to a BLASTn search of the NCBInr database in an attempt to match $C$. daubneyi sequences to any existing sequences with significant similarity. Further BLAST searches were performed against the SRA files available at SRA091604 (sheep), SRA039814 (goat) and SRA091607 (buffalo) with the transcriptome data for P. cervi [25] generated on an Ion Torrent ${ }^{\mathrm{mw}}$ PGM platform to identify sequences potentially unique to $C$. daubneyi or likely shared with other paramphistomes. To obtain a picture of the most active high-level functions occurring in our adult $C$. daubneyi specimens, the predicted peptide sequences generated through Transdecoder (https://transdecoder.github.io) within the Trinotate annotation process were extracted for the top $10 \%$ of mapped contigs (7379) and uploaded to the BlastKOALA annotation tool [26] for $\mathrm{K}$ number assignment of sequences categorized according to the KEGG Orthology system (ko00001).

Protein families representing members of the Phase I, II and III detoxification pathways were investigated within the $C$. daubneyi transcriptome. Sequences from members of the cytochrome P450 (CYP450) family identified in Cwiklinski et al. [27], the glutathione transferase (GST) from Morphew et al. [28] and the Fatty Acid Biding Protein (FABP) family from Morphew et al. [29] were used to BLAST the $C$. daubneyi transcriptome. The E value for BLAST analysis was set at 1 . All transcript BLAST hits were initially confirmed as CYP450s, GSTs or FABPs using BLAST analysis against the GenBank database. In addition, sequences were analysed for Interpro domains [30] specific to CYP450 (IPR023173 NADPH-cytochrome P450 reductase or IPR036396 cytochrome P450 superfamily for reductases and monooxygenases), GST (IPR036282 glutathione S-transferase, Cterminal domain superfamily and/or IPR004045 glutathione S-transferase, N-terminal) and FABP (minimum inclusion of IPR012674 Calycin supported with IPR031259 intracellular lipid binding protein, IPR000566 lipocalin/ cytosolic fatty-acid binding domain and IPR000463 cytosolic fatty-acid binding). Furthermore, FABPs were classified as FABPs using secondary structure prediction using PsiPred [31] looking for the characteristic 2 alpha helices and 10 beta sheets.

\section{Proteomics: sample collection}

Samples of rumen fluke parasites from naturally infected cattle were obtained from a local abattoir (mid-Wales, UK). Flukes were washed in warm $\left(39^{\circ} \mathrm{C}\right)$ phosphate-buffered saline (PBS) to remove rumen content contamination on collection, and transported directly to the laboratory. The PBS solution was replaced with a fresh volume for a further $10 \mathrm{~min}$ wash on arrival at the laboratory. Live parasites were then transferred into warm $\left(39{ }^{\circ} \mathrm{C}\right)$ DME culture media (DMEM) supplemented with 15 mM HEPES, 61 
$\mathrm{mM}$ glucose, $2.2 \mathrm{mM}$ calcium acetate, $2.7 \mathrm{mM}$ magnesium sulphate, $1 \mu \mathrm{M}$ serotonin and gentamycin $(5 \mu \mathrm{g} / \mathrm{ml})$ as described previously [32], allowing $1 \mathrm{ml}$ of culture media per fluke. After a 6-hour culture period, parasites were removed from the culture liquid and both parasites and liquid were snap frozen in liquid nitrogen prior to storage at $-80^{\circ} \mathrm{C}$.

\section{Protein sample isolation and 2D SDS-PAGE}

Excretory/secretory (ES) protein samples: a protease inhibitor cocktail (cOmplete ${ }^{\mathrm{m}}$ tablet, Roche, Welwyn Garden City, UK) was added to the liquid samples before being clarified by centrifugation at $45,000 \times g$ for $45 \mathrm{~min}$ at $4{ }^{\circ} \mathrm{C}$. The resulting supernatant was then concentrated using an Amicon ${ }^{\circ} 400 \mathrm{ml}$ stirred cell unit and an Ultra$\mathrm{cel}^{\circ} 10 \mathrm{kDa}$ MWCO regenerated cellulose ultrafiltration membrane disc (Merck Millipore, Darmstadt, Germany). Concentrated ES proteins were precipitated using an equal volume of ice cold $20 \% \mathrm{v} / \mathrm{v}$ TCA in acetone. Precipitated protein pellets were washed twice in ice cold acetone, dried at $-20{ }^{\circ} \mathrm{C}$ before solubilisation in buffer as described by Morphew et al. [32] Somatic soluble protein samples: whole parasite samples were homogenised in buffer containing $20 \mathrm{mM}$ potassium phosphate $(\mathrm{pH}$ 7.4), $0.1 \%$ v/v Triton $\mathrm{X} 100$ and a protease inhibitor cocktail tablet (Roche mini cOmplete ${ }^{\mathrm{rn}}$ ). Soluble protein samples were clarified by centrifugation at $100,000 \times g$ for $45 \mathrm{~min}$ at $4{ }^{\circ} \mathrm{C}$. Proteins were then precipitated and re-solubilised from the supernatant as for ES products.

Protein concentration was measured by the Bradford assay [33] and $17 \mathrm{~cm}$ immobilised pH gradient IPG strips (Bio-Rad, Watford, UK) were rehydrated with a total of 250 and $500 \mu \mathrm{g}$ of protein for the ES and somatic samples respectively. A total sample volume of $300 \mu \mathrm{l}$ was used to rehydrate and focus the $17 \mathrm{~cm} \mathrm{pH} \mathrm{3-10} \mathrm{IPG} \mathrm{strips}$ (Bio-Rad) at $20{ }^{\circ} \mathrm{C}$ for separation in the first dimension. Linear IPG strips were used for somatic samples with non-linear IPG strips used for improved resolution of protein spots with the ES samples. IPG strips were focussed to between 60,000 and 80,000 Vh using the Protean IEF Cell (Bio-Rad). Each IPG strip was then equilibrated for $15 \mathrm{~min}$ in equilibration buffer [containing $50 \mathrm{mM}$ Tris- $\mathrm{HCl} \mathrm{pH}$ 8.8, $6 \mathrm{M}$ urea, 30\% glycerol (v/v) and $2 \%$ SDS $(\mathrm{w} / \mathrm{v})$ ) with the addition of DTT (Melford, UK) at 10 $\mathrm{mg} / \mathrm{ml}$ ] followed by a second equilibration with IAA (Sigma-Aldrich, Gillingham, UK) at $25 \mathrm{mg} / \mathrm{ml}$ replacing DTT [34]. The IPG strips were separated in the second dimension on the Protean II system (Biorad) using 14\% polyacrylamide gels as described by Morphew et al. [32]. Gels were then fixed in $40 \%(\mathrm{v} / \mathrm{v})$ ethanol, $10 \%(\mathrm{v} / \mathrm{v})$ acetic acid and stained using Colloidal Coomassie [35].

\section{Imaging and spot identification}

Coomassie stained gels were imaged using a GS-800 calibrated densitometer (Bio-Rad) set for coomassie stained gels at 400 dpi. Gel images were analysed using Progenesis PG220 v.2006 using the 'Mode of non-spot' background subtraction method. Average gels were created from 4 replicate gels for the somatic and ES samples respectively and normalised spot volumes were calculated using the 'Total spot volume multiplied by total area' method to determine the most abundant protein spots.

\section{Mass spectrometry and data analysis}

The 50 most abundant spots were identified for both ES and somatic samples on $17 \mathrm{~cm}$ SDS-PAGE gels using Progenesis and excised before being subjected to tryptic digest [34]. Digested protein samples were resuspended in $20 \mu \mathrm{l} 0.1 \%$ formic acid for LC Tandem mass spectrometry (MS/MS) analysis on an Agilent 6550 iFunnel Q-TOF mass spectrometer with a Dual AJS ESI source coupled to a 1290 series HPLC system (Agilent, Cheshire, UK). A $2.1 \times 50 \mathrm{~mm} 1.8$ micron Zorbax Eclipse Plus C18 column was used; $10 \mu \mathrm{l}$ of sample was injected for analysis. Liquid chromatography was performed at a flow of $0.1 \mathrm{ml} / \mathrm{min}$ with a piece-linear gradient using water with $0.1 \% \mathrm{v} / \mathrm{v}$ formic acid (A) and acetonitrile with $0.1 \% \mathrm{v} / \mathrm{v}$ formic acid (B) (0-3\% B over $2 \mathrm{~min}, 3-40 \%$ B over $7 \mathrm{~min}, 40-100 \%$ B over $1 \mathrm{~min}$, hold at 100\% B for $1 \mathrm{~min}$ ).

Ions were generated using a Dual AJS ESI source. MS/MS was performed in Auto MS/MS mode in the 300-1700 range, at a rate of 0.6 spectra per second, performing MS2 on the 5 most intense ions in the precursor scan. Masses were excluded for $0.1 \mathrm{~min}$ after MS2 was performed. Reference mass locking was used for internal calibration using the mass of 922.009798 Da. Peak lists were generated using Mass Hunter Qualitative Analysis software (version B.06.00) using Molecular Feature Extraction and exported as Mascot Generic Files. MSMS data was analysed with MASCOT (Version 2.4.1; www.matrixscience.com) using an MS/MS Ions search on standard settings (precursor tolerance \pm 1.2 Da, fragment ion tolerance $\pm 0.6 \mathrm{Da}$ ) for the enzyme trypsin, allowing up to 2 missed cleavages, carbamidomethyl as a fixed modification and oxidation of methionine as a variable modification. Spectra were searched against the in-house transcript assembly for C. daubneyi described in the present study, with sequence hits reported from MASCOT compared to the functionally annotated transcript data for protein ID. The mass spectrometry proteomics data have been deposited to the ProteomeXchange Consortium via the PRIDE partner repository with the dataset identifier PXD007772 and null. UniProt identifiers from the transcript BLASTp annotation data which matched to each protein spot following LC MS/MS were then uploaded to the UniProt mapping application (uniprot.org/mapping, accessed 03/ $12 / 2015)$ to obtain descriptive data on the protein matches, organism ID and GOslim information for each 
matched protein. SignalP and TMHMM matches for ES proteins, along with gene component expression levels as FPKM values were extracted from the transcript annotation data to match each hit. Evidence of the 50 most abundant proteins being identified as packaged in exosome-like vesicles in previous studies was identified by matching protein descriptions to those obtained in previous helminth exosome studies [36-39] or in the ExoCarta database [40].

\section{Extracellular-like vesicle visualisation}

Isolation of extracellular-like vesicles was performed by ultracentrifugation of ES products $(700 \times g$ for $20 \mathrm{~min}$ at $4{ }^{\circ} \mathrm{C}$ ), followed by $120,000 \times g$ for $80 \min$ at $4{ }^{\circ} \mathrm{C}$, using a Optima $^{\text {TM }}$ L-100 XP ultracentrifuge (Beckman Coulter, High Wycombe, UK) using a Type $70 \mathrm{Ti}$ rotor as described by Nowacki et al. [39] with the addition of a 2.0 $\mu \mathrm{m}$ syringe filter step before the final pelleting and re-suspension to eliminate contaminating bacterial components which may have been present from the rumen. Imaging and identification of extracellular vesicles using a Jeol 1010 transmission electron microscope (TEM) and size-selective criteria $(30-100 \mu \mathrm{M})$ was performed as previously described [39].

\section{In vitro gas production culture}

Liquid fraction rumen fluid for the in vitro culture protocol was collected from 5 individual bovine rumens, each visually inspected and declared free from rumen fluke infection before fluid collection. Rumen fluid was collected immediately post-mortem after inspection upon opening of the rumens by straining the rumen contents through a layer of muslin cloth into a pre-warmed thermos collection flask. Flasks were filled almost to the brim to minimise the headspace for oxygenation of the rumen fluid. In total, $40250 \mathrm{ml}$ Duran $^{\mathrm{Tm}}$ bottles (ThermoFisher Scientific, Paisley, UK) were used as the culture vessels. Half of these bottles were supplied with $1 \mathrm{~g}$ dried and ground grass silage as a fermentation substrate for microbial activity. Half of the bottles were left empty. These groups were then split, with half of the silage containing and half of the empty bottles to receive rumen fluke and half without in order to provide both positive and negative controls for the fermentation. A single replicate bottle for each of the 5 animals sampled for rumen fluid was utilised in each treatment and treatments were replicated at 2 different time points; 6 and 24 hours. Culture treatment groups were therefore as follows: Group 1 (Blank; no rumen fluke and no silage), Group 2 (Fluke only; rumen fluke but no silage), Group 3 (Rumen fluke and Silage) and Group 4 (Silage only). On return to the laboratory, rumen fluid from each of the 5 individual animals was mixed 1:1 with pre-prepared Coleman-Simplex buffer based on the medium described by Coleman [41]. This mixture was maintained in a $39^{\circ}$ $\mathrm{C}$ water bath and continuously flushed with $\mathrm{CO}_{2}$ to maintain anaerobic conditions during dispensing. To each culture bottle, $100 \mathrm{ml}$ of the $50 \%$ rumen fluid mixture was added and for fluke-positive bottles 10 rumen fluke were added. Bottles were sealed using ANKOM RF Gas Production Measurement System units to record cumulative gas production and allow for automated pressure release. Based on the number of parasites present in a high burden rumen fluke infection detected in a previous slaughterhouse study $(11,895$ in a single bovine) [42] and an estimated rumen volume of $100 \mathrm{l}$, 10 parasites were added to the $100 \mathrm{ml}$ culture vessels in order to simulate a high in vivo burden.

\section{Gas production analysis}

The volumes of gas produced were measured using an ANKOM RF Gas Production Measurement System (Macedon, NY, USA), with data collected every $5 \mathrm{~min}$ from each bottle over a $24 \mathrm{~h}$ period. Cumulative gas production levels obtained from the ANKOM RF Gas Production system were fitted to the exponential equation using the Neway Excel curve-fitting program, Fit Curve [43] (Obtained from http://www.macaulay.ac.uk/IFRU/ resrc_fcurve.html, April 2016) as described by Ørskov \& McDonald [44].

\section{Metabolite analysis}

VFA analysis was performed using $4 \mathrm{ml}$ of sample from each bottle and mixed with $1 \mathrm{ml}$ of $20 \% \mathrm{v} / \mathrm{v}$ orthophosphoric acid containing $4 \mathrm{mM}$ 2-ethyl butyric acid (internal standard). During storage, VFA samples had settled to provide a clear supernatant within each $15 \mathrm{ml}$ falcon tube, $2 \mathrm{ml}$ of this was syringe filtered through a $0.45 \mu \mathrm{m}$ nylon syringe filter tip (ChronusFilter, SMI-LabHut Ltd, Gloucester, UK) and transferred into a GC vial (Chromacol, Altrincham, UK). Vials were analysed using Gas Chromatography on a Varian CP-3380 GC instrument with a HP-FFAP $25 \mathrm{~m} \times 0.53 \mathrm{~mm}$ I.D. $\times 1 \mu \mathrm{m}$ film thickness column (J and W Scientific, USA). Data collection and analysis was carried out using the Varian Galaxie Chromatography Workstation (software version 1.9.3.2.) to calculate the $\mathrm{mmol} / \mathrm{l}$ concentration of different VFAs within each vial. Data was then imported into Microsoft Excel for calculation of the $\mathrm{mmol} / \mathrm{l}$ concentration of VFAs within the in vitro rumen fermentation samples.

Stored culture samples were defrosted overnight at $4{ }^{\circ} \mathrm{C}$. Ammonia levels were determined from the contents of each fermentation bottle. Each sample was put into $10 \%$ [w/v] TCA and centrifuged for $15 \mathrm{~min}$ at $14,000 \times g$ at $4{ }^{\circ} \mathrm{C}$. In preparation for analysis the sample was diluted in deionised water 5 -fold. A sample of this dilution was mixed with Reagent A (13 mg/l NaOH, $4 \mathrm{mg} / \mathrm{l}$ EDTA), Reagent B ( $10 \mathrm{~g} / \mathrm{l}$ phenol, $50 \mu \mathrm{g} / \mathrm{l}$ sodium nitroprusside) and Reagent 
C (5 g/l of $\mathrm{NaOH}$ in $15 \%$ (v/v) sodium hypochlorite). Reactions were then performed for $15 \mathrm{~min}$ in the dark at $39^{\circ} \mathrm{C}$ before reading the absorbance at $630 \mathrm{~nm}$.

\section{Protozoan counts}

Samples of the rumen culture liquid were diluted 1:1 in $0.9 \%(\mathrm{w} / \mathrm{v}) \mathrm{NaCl}, 4 \%(\mathrm{v} / \mathrm{v})$ formalin to preserve the protozoans. A minimum of $24 \mathrm{~h}$ before counting, methylene blue dye was added to stain the protozoans. Samples were then diluted 1:20 in $\mathrm{NaCl}$ /formalin and mixed by pipetting before $10 \mu \mathrm{l}$ of this dilution was placed on a microscope slide under a cover slip for examination using the 20x magnification objective lens on a bright field light microscope. All visible protozoans in the $10 \mu \mathrm{l}$ volume placed under the cover slip were counted. Samples from each fermentation bottle were counted in duplicate and an average count, per $10 \mu \mathrm{l}$, calculated. Average counts were then corrected for the dilution factors used during sample preparation and the total counts of protozoans present within each fermentation bottle analysed by one-way ANOVA for both the 6 and $24 \mathrm{~h}$ time points as described below for the 5 replicates.

\section{Statistical analysis}

GenStat software (16th edition, VSN International, UK) was used to perform a one-way ANOVA test with Bonferroni corrections for post-hoc analyses, for each variable measured at each respective time point to detect differences occurring from either fluke or silage treatments of fermentation vessels. For each ANOVA, animal (the 5 donor animals from which rumen fluid was sampled for the fermentations) was used as a blocking factor in order to account for individual variation in the rumen fluid sample pools.

\section{Analysis of propionate production pathway genes present in the C. daubneyi transcriptome}

Known genes from the related trematode species, for which data exists in the KEGG database, S. mansoni, along with data for the nematode $C$. elegans as the best annotated of the 5 nematode species for which data was available in KEGG were used to identify the $C$. daubneyi propionate pathway. Species-specific maps of the propionate production pathway (map 00640) were viewed via the KEGG pathway application and for each enzyme code indicated, as identified in the respective data for $S$. mansoni and C. elegans, peptide sequences were downloaded and a local tBLASTn search performed using BioEdit [45] against the mapped $C$. daubneyi transcript contigs with a stringent E-value score of $1.0 \times 10^{-80}$ applied to reported hits. Using the user data mapping application within KEGG pathway maps enzyme codes for which actively transcribed genes were identified were highlighted on the propionate metabolism map.

\section{Results}

Transcriptome analysis

This Transcriptome Shotgun Assembly project has been deposited at DDBJ/EMBL/GenBank under the accession GFUT00000000. The version described in this paper is the first version, GFUT01000000. From a total of $226,188,786$ raw reads, the Trinity transcript assembly generated 103,541 unique contigs (Table 1). Of the contigs generated during the Trinity assembly process, 73,792 mapped back to the raw Illumina sequencing reads. Only these mapped reads were included in downstream analysis. From these 73,792 unique contigs, 54,617 individual gene components (defined in Trinotate as genes and their associated duplicates, gene parts and fragments in the absence of a reference genome) were identified of which $69.51 \%$ had no annotation associated with them after functional analysis using the Trinotate pipeline. Gene components were sorted by cumulative FPKM values for all isoforms identified and sequences of the 50 most highly expressed gene components (longest isoform shown) were identified (Additional file 1: Table S1). Of these gene components, 37 had a top annotation hit to another helminth species, 9 had no successful annotation and 4 hit to other organisms (ciliate protozoa (2), zebrafish and a yeast). These most highly expressed genes were largely annotated as eggshell and vitelline proteins, required for reproduction, followed

Table 1 De novo transcriptome assembly summary statistics for adult $C$. daubneyi specimens collected from a natural bovine infection following RNAseq and Trinity assembly

\begin{tabular}{ll}
\hline Category & Statistic \\
\hline Total raw reads & $226,188,786$ \\
Per replicate & \\
A & $95,417,496$ \\
B & $74,644,572$ \\
C & $56,126,718$ \\
GC percentage & 47 \\
Total assembled contigs generated & 103,541 \\
Contigs mapped to raw reads & 73,792 \\
Average contig length (bp) (mapped) & $738(892)$ \\
Maximum contig length (bp) & 24,404 \\
Minimum contig length (bp) & 224 \\
\% mapped contigs without BLASTx/p annotation & $62.94 / 62.74$ \\
\% Mapped contigs with Signal Peptide (SigP) & 1.80 \\
\% Mapped contigs with Transmembrane & 5.77 \\
Domain (TM) & \\
\% Mapped contigs with both TM+SigP & 0.65 \\
Unique gene components identified & 54,617 \\
(from mapped contigs) & \\
\% gene components without BLASTx/p annotation & 69.51 \\
\hline
\end{tabular}


by associations with respiratory processes, tubulin, ferritin and a number of unannotated or uncharacterised transcripts were identified (Additional file 1: Table S1). A full list of the identified transcripts is provided in Additional file 1: Table S2.

The 50 gene components with the highest FPKM values that had no annotation data from the Trinotate analysis were additionally searched against the NCBInr database (http://blast.ncbi.nlm.nih.gov/Blast.cgi, accessed 14/12/2015) and the SRA files generated from Ion Torrent $^{\text {tw }}$ sequencing of the transcriptome of the related paramphistome P. cervi [25] [available under the accession numbers SRA091604 (sheep), SRA039814 (goat) and SRA091607 (buffalo): Additional file 1: Table S3]. Only 1 additional significant hit was returned from the NCBInr database search, matching gene component TR26203|c0_g1 to a C. daubneyi cox1 gene with $100 \%$ homology (8\% coverage) to accession number KJ574061.1. BLAST searches against the SRA files for $P$. cervi found significant matches for 38 of the 50 gene components searched, suggesting that these unidentified gene components may be common across the paramphistomes and the $12 / 50$ unmatched gene components are potentially unique to C. daubneyi.

In total, 17,149 sequences were matched to $\mathrm{GO}$ terms (level 3) during the Trinotate annotation process (Fig. 1). At level 3, the majority of GO terms identified under the category Biological Process were related to organic substance, primary and cellular metabolic processes and single-organism processes. Terms identified for Molecular Functions were mostly linked to binding activities and Cellular Component terms were in the majority related to intracellular and membrane component terms. Categorisation of the predicted peptide sequences corresponding to the top $10 \%$ of expressed contigs using the BlastKOALA tool and KEGG KO orthology system showed that highly expressed contigs were most commonly linked to genes within the KEGG database associated with genetic information processing, cellular processes, human diseases (not including parasitic infections) and environmental information processing. Of the peptide sequences uploaded, only $28.7 \%$ could be annotated to KO numbers in the KEGG database.

In summary, sequences for which an annotation could be obtained, matches were mostly common to related trematode, cestode or nematode species as would be expected. The transcriptome assembly produced mapped reads of which $62.94 \%$ appeared to be potentially novel sequences with no matches identified during the Trinotate (V2.0) functional annotation process, highlighting the dearth of current data available in relation to the paramphistomes and that these parasites may be quite unique amongst the trematodes. This was further exemplified by the attainment of only $28.7 \%$ annotation of

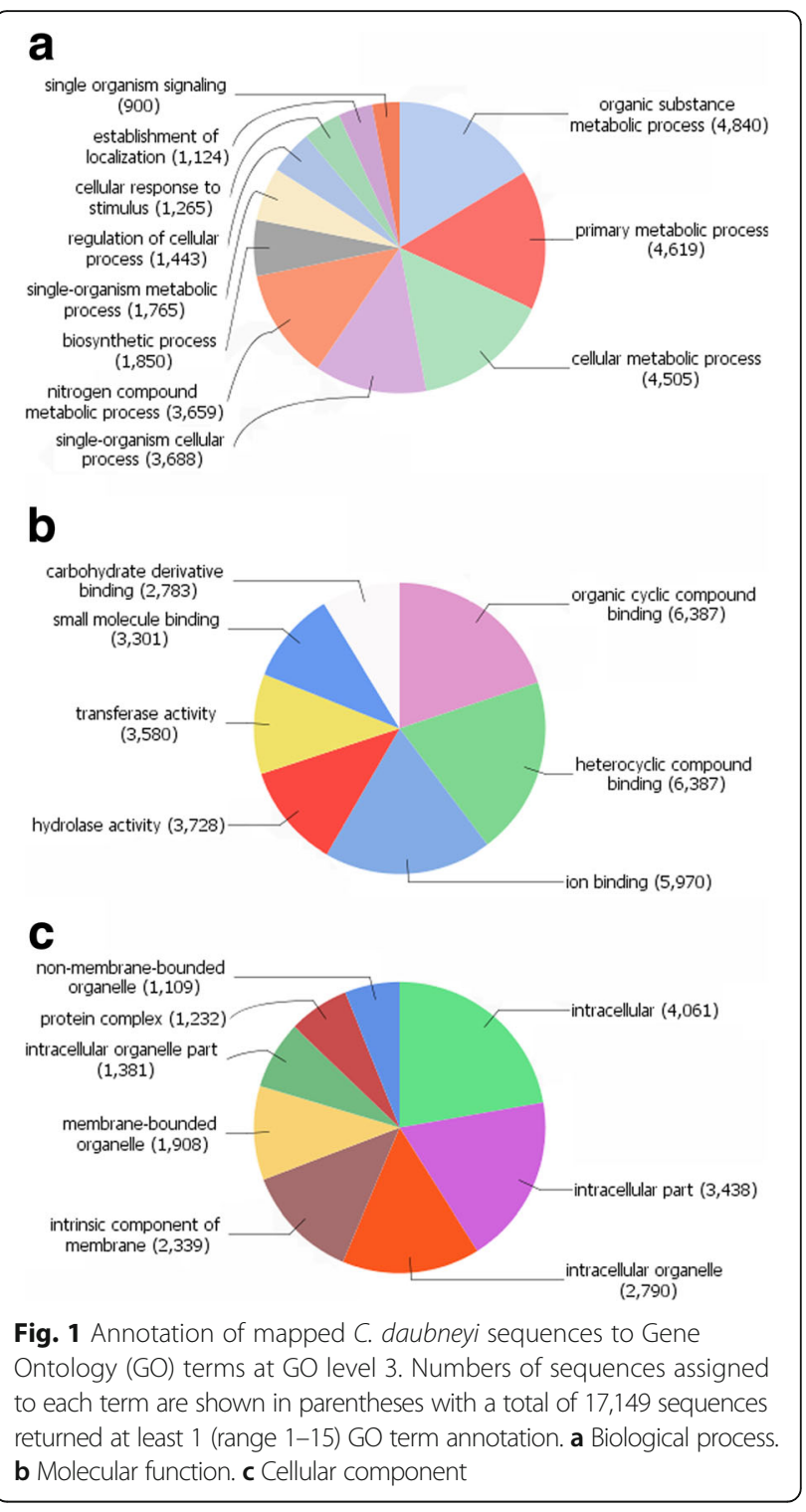

predicted peptides corresponding to the 10\% most expressed contigs submitted through BlastKOALA for annotation to functional orthologous groups in the KEGG database.

As a case study, phase I, II and III detoxification components were investigated given the likely role they play in both anthelmintic detoxification and detoxification for survival within the rumen environment. Phase I, II and III target families, namely CYP450s, GSTs and FABPs respectively, were all represented in the $C$. dauvbneyi transcriptome. Analysis of the phase I CYP450s identified one gene product corresponding to a CYP450 monooxygenase and one CYP450 reductase. Both were confirmed as such with key motifs for the monooxygenase (IPR036396 cytochrome P450 superfamily) and reductase (IPR023173 NADPH-cytochrome P450 reductase). Phase II detoxification demonstrated an increase in sequences identified 
from BLAST analysis. A total of 19 GST gene products were identified representing 4 established GST classes. Two gene products represented Omega class GSTs whilst a single gene product was confirmed as a zeta class GST. Of the more abundant platyhelminth classes $2 \mathrm{mu}$ class GSTs were identified along with a further 14 sigma class like GST gene products. All GST sequences were confirmed as GSTs using the Interpro domain prediction of IPR036282. Finally, investigating the phase III sequestration FABPs revealed a total of 17 full length FABPs along with 2 further partial sequences representing 19 potential FABPs. Of note are FABP gene products representing the Fasciola type V FABPs and a single representative for Fasciola type III, IV and VII (Additional file 2: Figure S1). Of interest is the expansion of a two groups of $C$. daubneyi FABPs, containing two and ten FABP isoforms designated CdFABP IL 1 and CdFABP IL2 respectively, that align more to vertebrate ileal and liver FABPs than they do Fasciolids or other platyhelminths.

\section{Proteomic profiles}

Both in vitro cultured ES and somatic proteome samples produced consistent 2D gel profiles allowing high quality Progenesis average gels to be generated (Figs. 2 and 3, respectively), with the most abundant 50 spots from each average gel identified. These spots were then excised and subjected to tryptic digest and LC MS/MS, with the resulting peak spectra searched against our new functionally annotated $C$. daubneyi transcript database for protein identification, with putative spot identifications in Tables 2 and 3 for ES and somatic samples, respectively (full details are provided in and detailed further in Additional file 1: Tables S4 and S5). Only 1 spot from the somatic profile (spot 50) failed to return any hit and in total 6 spots (numbers 7, 15, 18, 20, 28 and 45 ) in the ES profile only returned hits with a MASCOT score below the significance threshold of 49 . The most highly abundant spots in the ES profile were identified as uncharacterised proteins belonging to the calycin superfamily/fatty acid binding protein family and represent CdFABP III (TR17138), CdFABP IL1 (TR14337) and CdFABP IL2 (TR18162). Identified proteins also included peptidases and proteases (including cathepsins) and glutathione transferase (GST) proteins which are known for their role in detoxification and protein-protein interactions. Of note were the identification of GSTs representing both $\mathrm{mu}$ and sigma class GSTs in the ES products but limited to one representative of both (isoforms of TR17112 mu class and TR21279 sigma-like). In the somatic profile uncharacterised proteins were again common and largely identified as fatty acid binding protein (FABP) family proteins representing CdFABP III (TR17138), CdFABP IL1 (TR15960) and CdFABP IL2 (TR18162). GSTs were also abundant with representatives

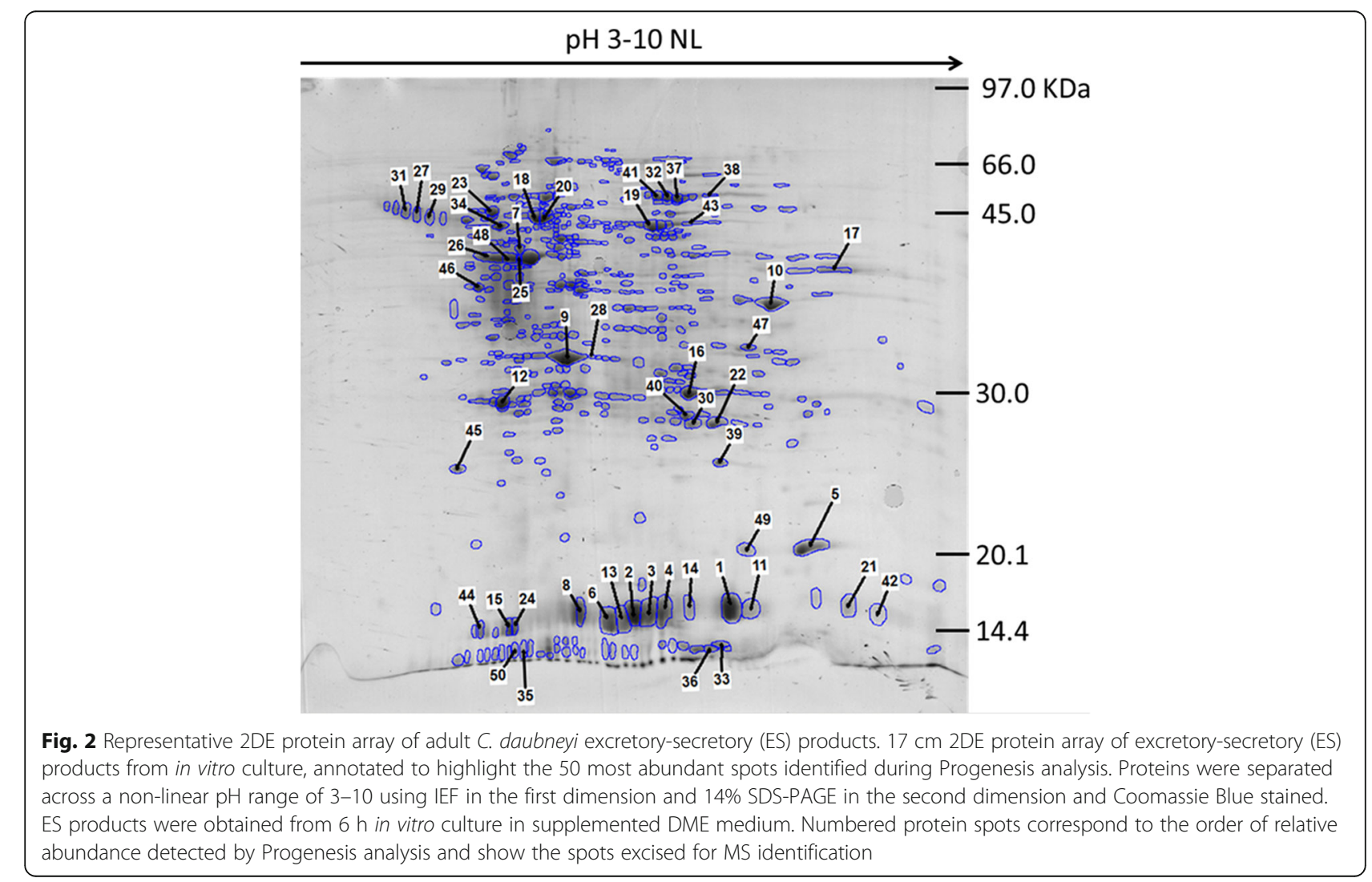




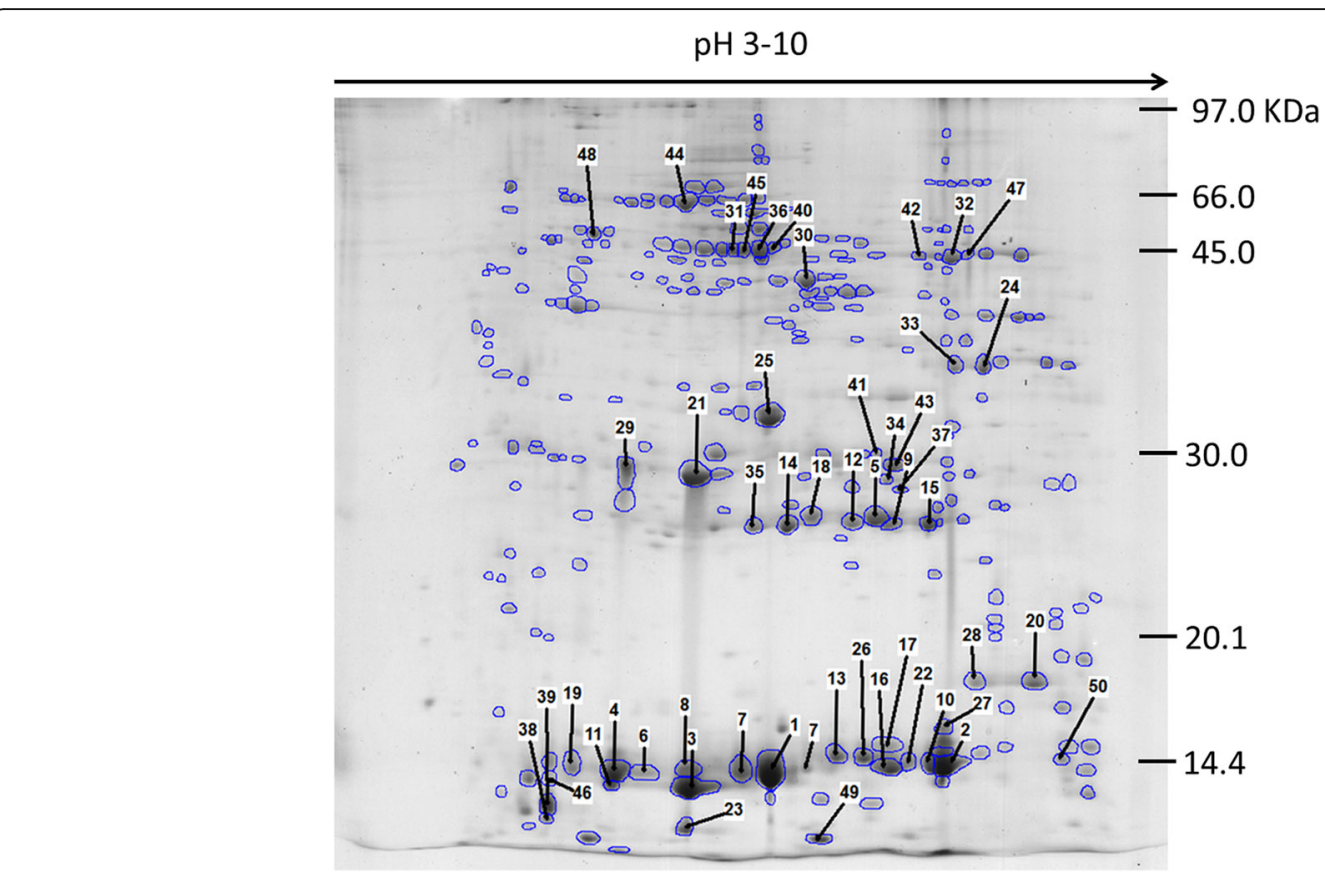

Fig. 3 Representative 2DE protein array of adult C. daubneyi soluble somatic proteins. $17 \mathrm{~cm}$ 2DE protein array of soluble somatic proteins annotated to highlight the 50 most abundant spots identified during Progenesis analysis. Proteins were separated across a linear pH range of 3-10 using IEF in the first dimension and 14\% SDS-PAGE in the second dimension and Coomassie Blue stained. Numbered protein spots correspond to the order of relative abundance detected by Progenesis analysis and show the spots excised for MS identification

from both mu and sigma-like GST classes characterised by TR17112 and TR21279 isoforms respectively mirroring that of the ES profile abundant GSTs. In addition, dehydrogenases/reductases and globins featured prominently in the somatic proteome.

Those protein spots which had top matched hits to gene components in the in-house transcriptome assembly which were not annotated through Trinotate functional analysis or BLASTx searches of the matched contig sequence through the NCBInr database (2 spots in the somatic profile and 2 in the ES profile) may be previously unknown proteins which are present in paramphistomes or even unique to $C$. daubneyi. Matching of FPKM top gene components to the most abundant protein spot identifications seen with the generated proteomic data was seen with 5 separate gene component identifications (TR17138, TR18162, TR17982, TR22034 and TR20361). All 5 were identified in the ES profile, representing 17 of the top 50 protein spots, and 3 of these gene components (TR17138, TR18162 and TR17982) were identified in the somatic profile, representing 15 of the 50 most abundant proteins. Interestingly, TR17138 and TR18162, both identified as FABPs (CdFABP III and CdFABP IL2), constituted the vast majority of matches between gene components and putative protein identifications (13 of 17 identifications in the ES proteome and 13 of 15 identifications in the somatic proteome).
TEM imaging of vesicle enriched in vitro culture media samples indicated the release of extracellular vesicles (EVs) by rumen fluke parasites in vitro (Fig. 4). The likely presence of exosome-like EVs is indicated by the identification of appropriately sized vesicles ranging in diameter from 30 to $100 \mathrm{~nm}$ [39]. Of the top 50 most abundant proteins (Table 2) identified in the ES proteome profile $46 \%(23 / 50)$ contained proteins which have previously been identified as packaged and released in extracellular vesicles from helminth species or are found listed in the ExoCarta database [40] as highlighted in Table 2 and detailed further in Additional file 1: Table S4.

\section{Gas production study}

Statistical analysis of calculated cumulative gas production volumes, ammonia concentration and protozoal counts did not identify any significant differences attributable to the presence of rumen fluke at either the 6 or 24-h time points. Significant differences were detected between the silage only (Group 4) and blank treatment (Group 1) bottles in respect of their protozoal counts at $24 \mathrm{~h}$ (Table 4), which was attributed to the respective presence/lack of grass silage fermentation substrate.

With the measurements of VFA profiles, silage was seen to have a significant impact on VFA concentrations as expected, with significant differences seen between silage-positive and -negative groups at $6 \mathrm{~h}$ for total VFA 


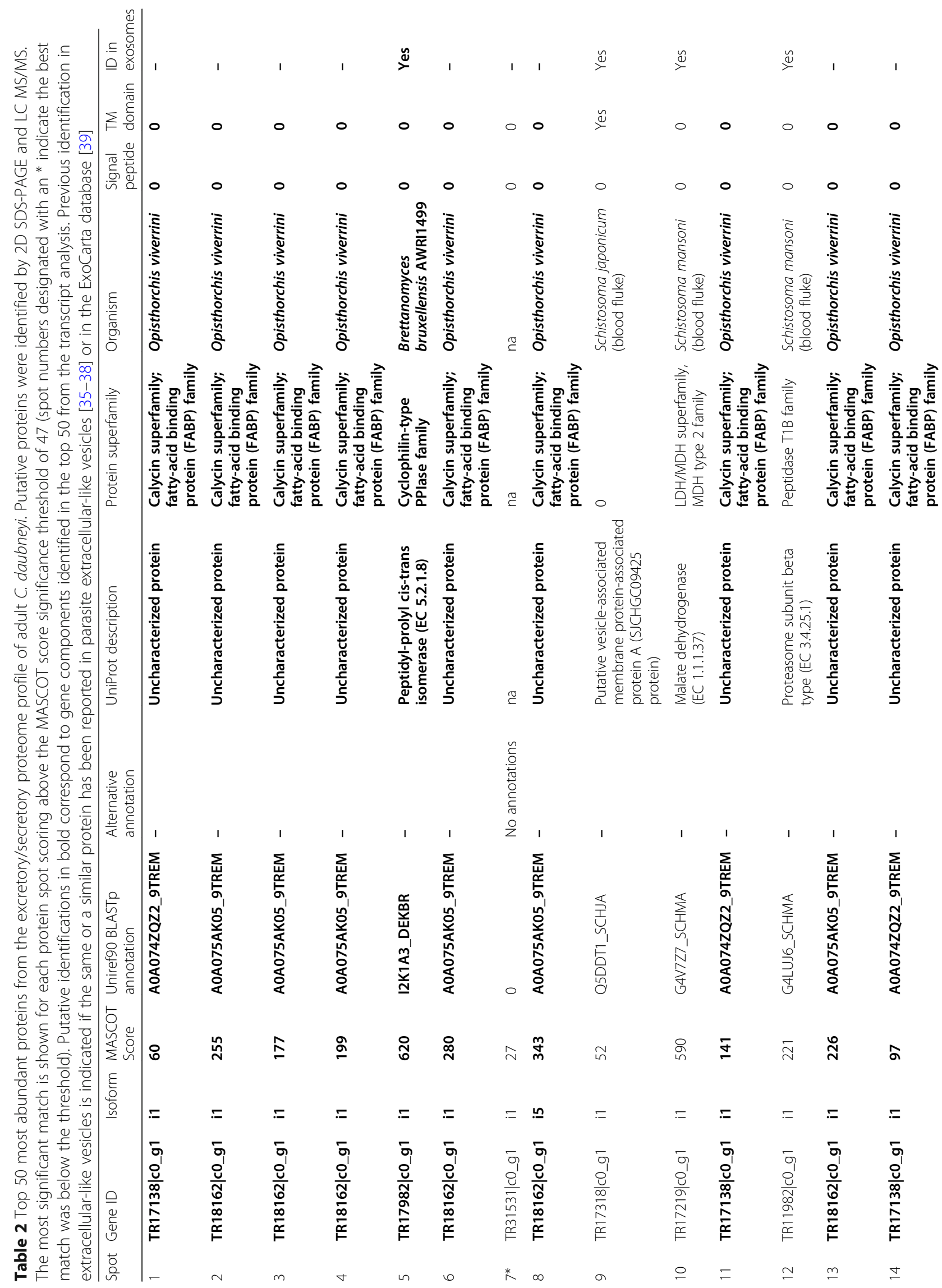




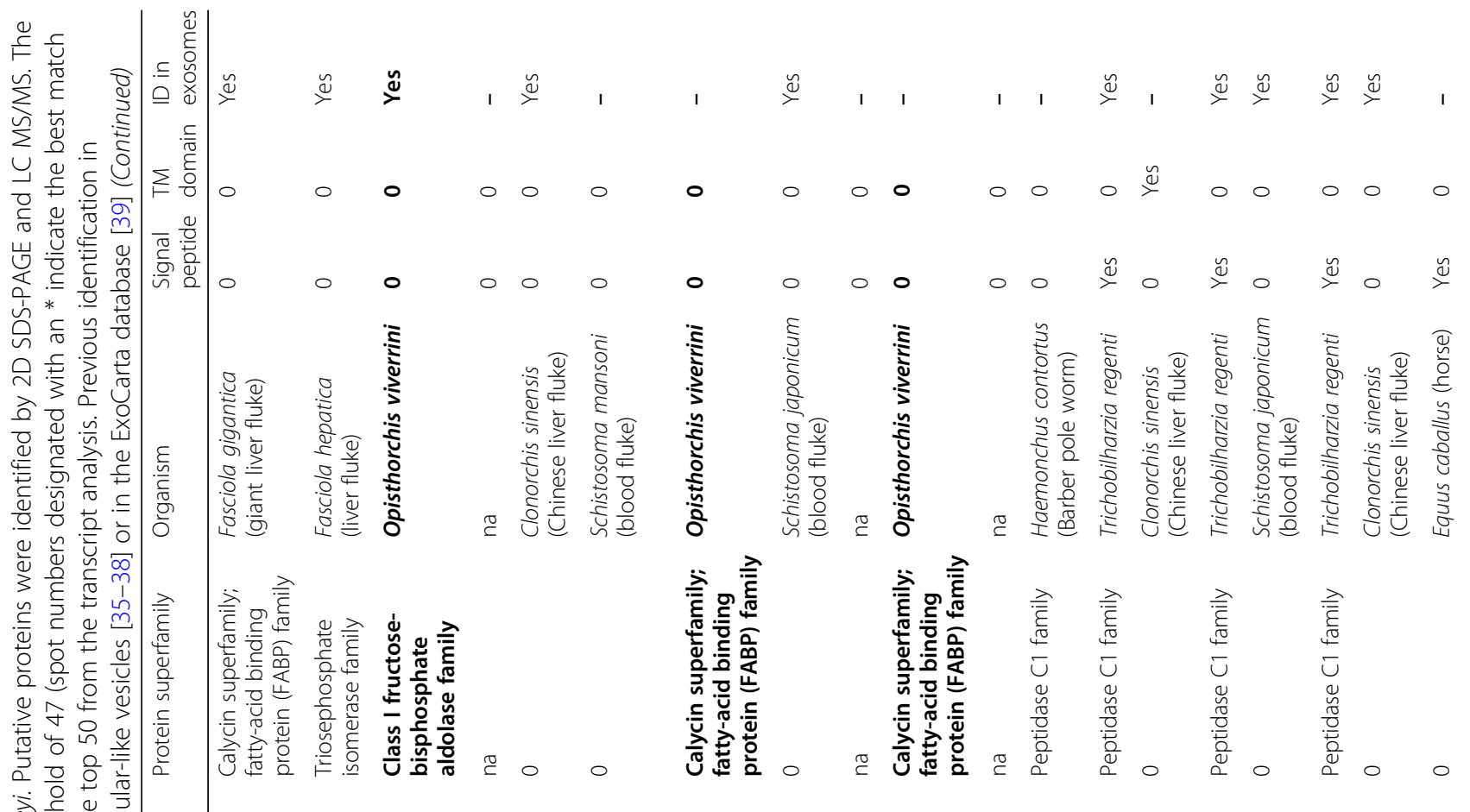

\section{\&
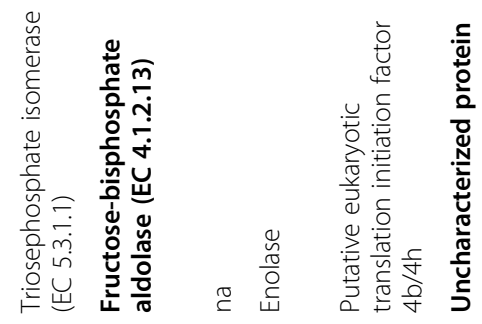
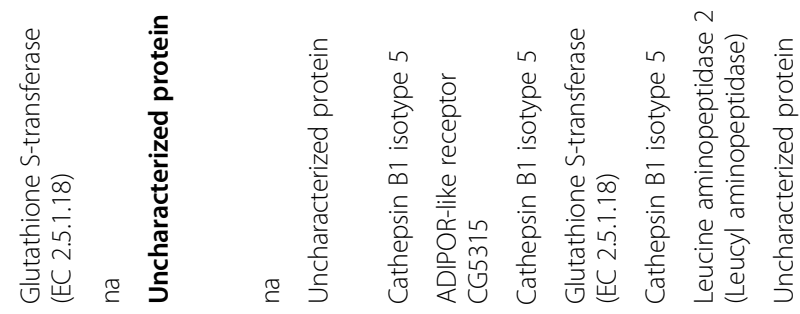

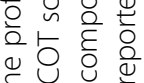

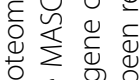

흔

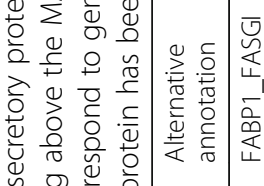

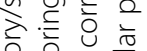

원 응

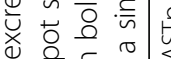

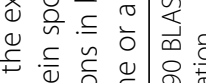

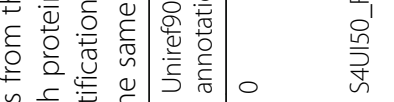
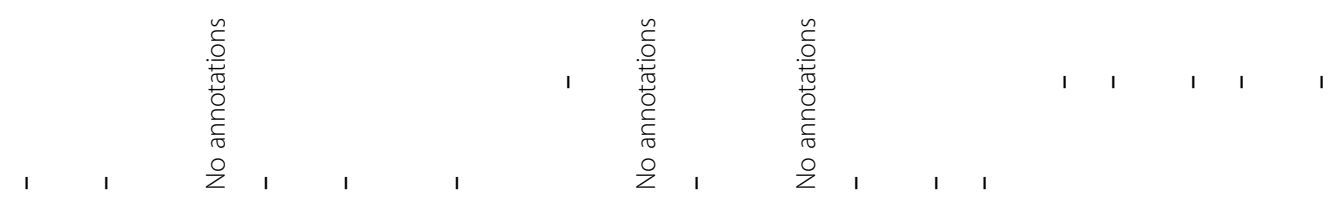

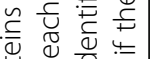

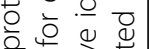

$+F$

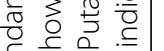

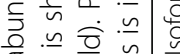

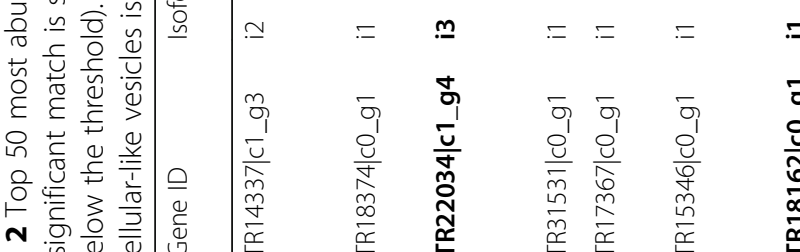

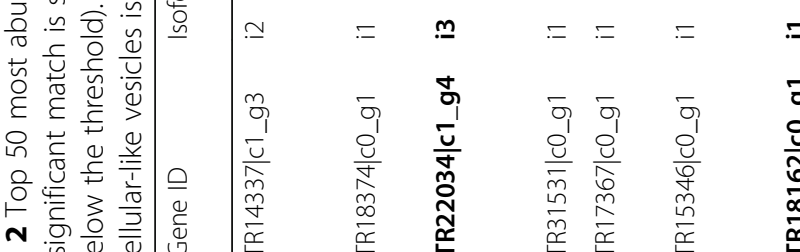

N

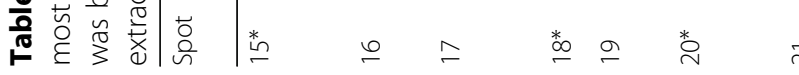

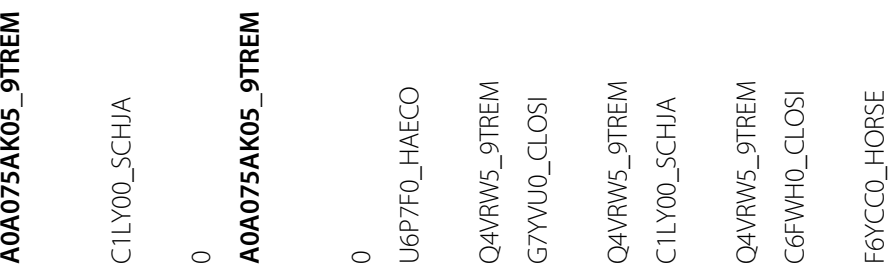

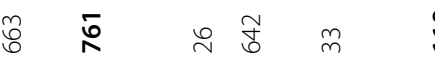

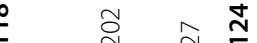

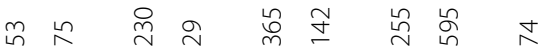

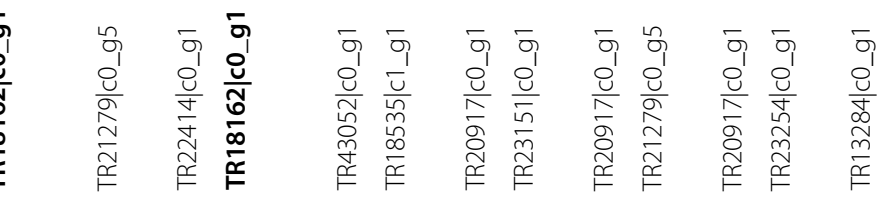

$\bar{\sim} \quad \approx \stackrel{*}{\sim} \underset{\sim}{\triangleleft}$

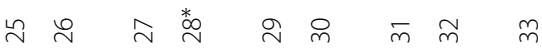




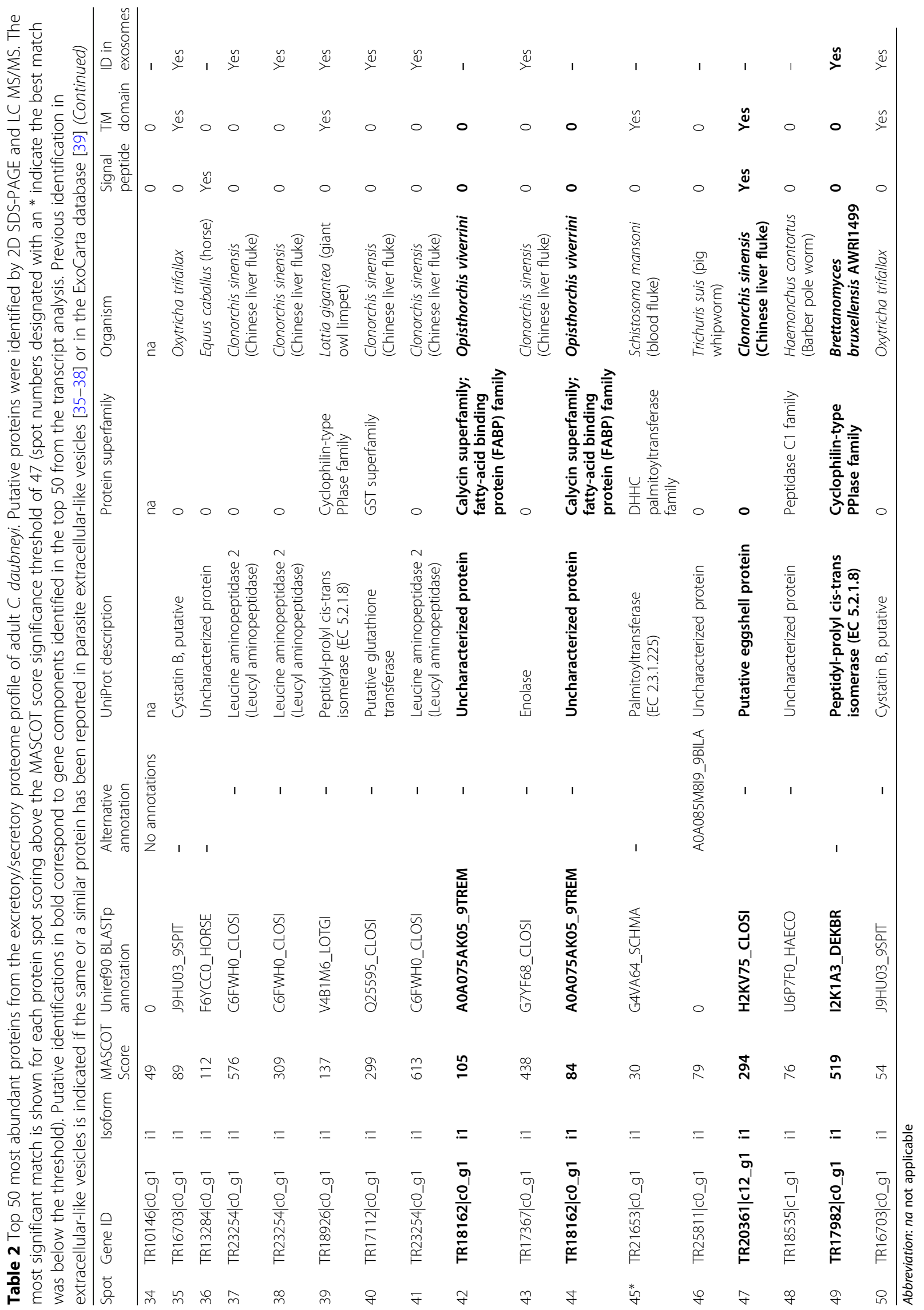




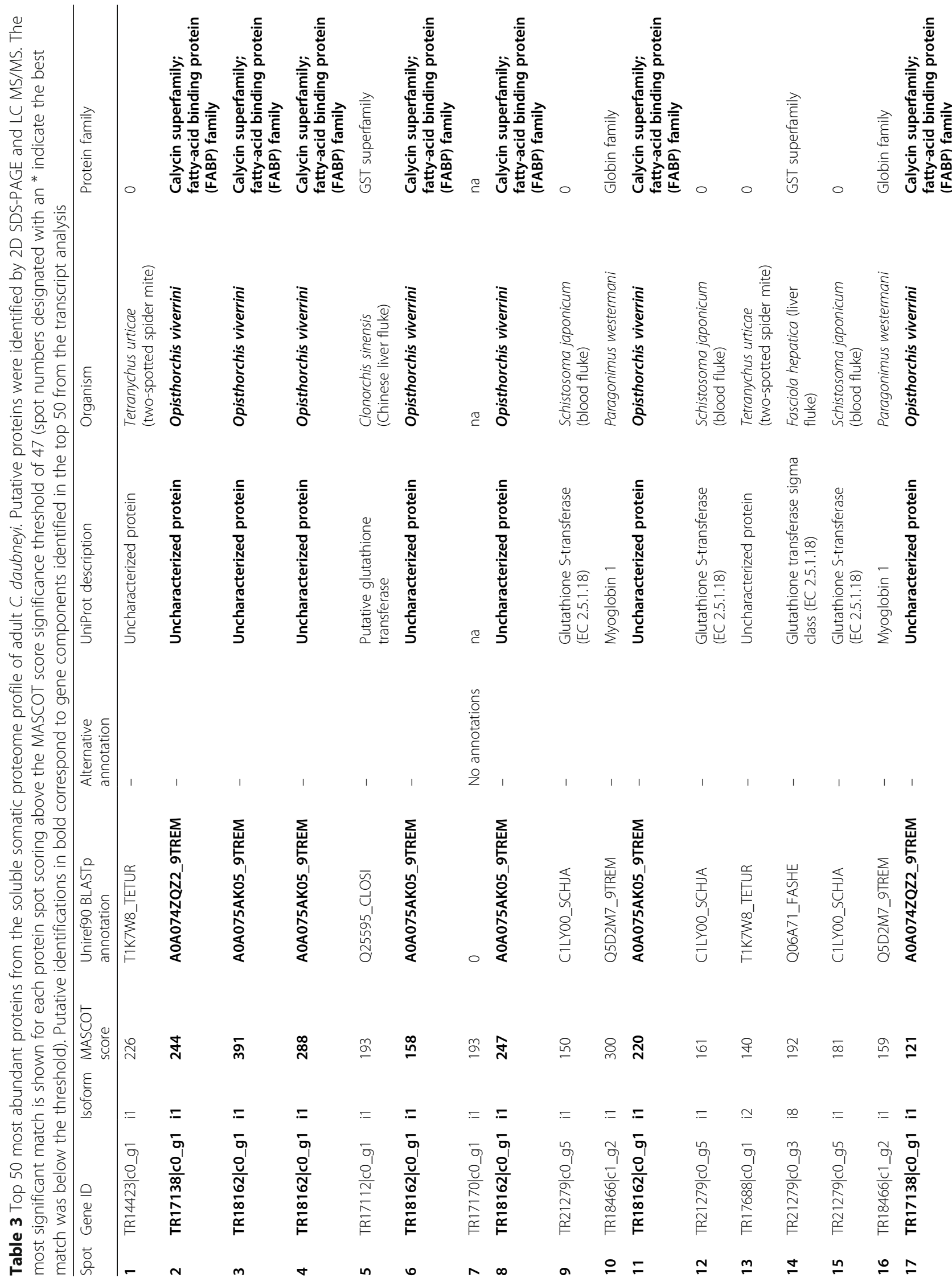




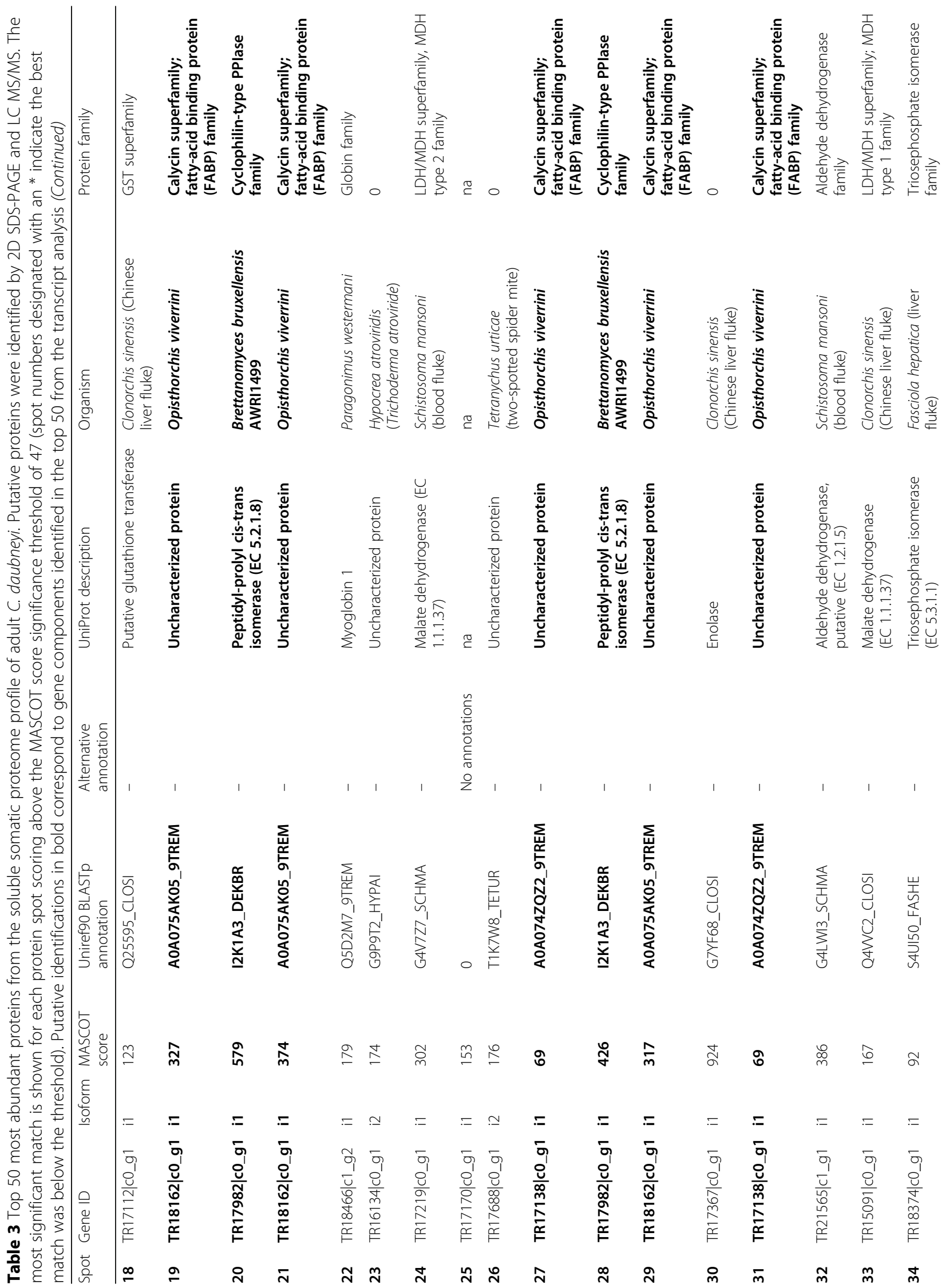




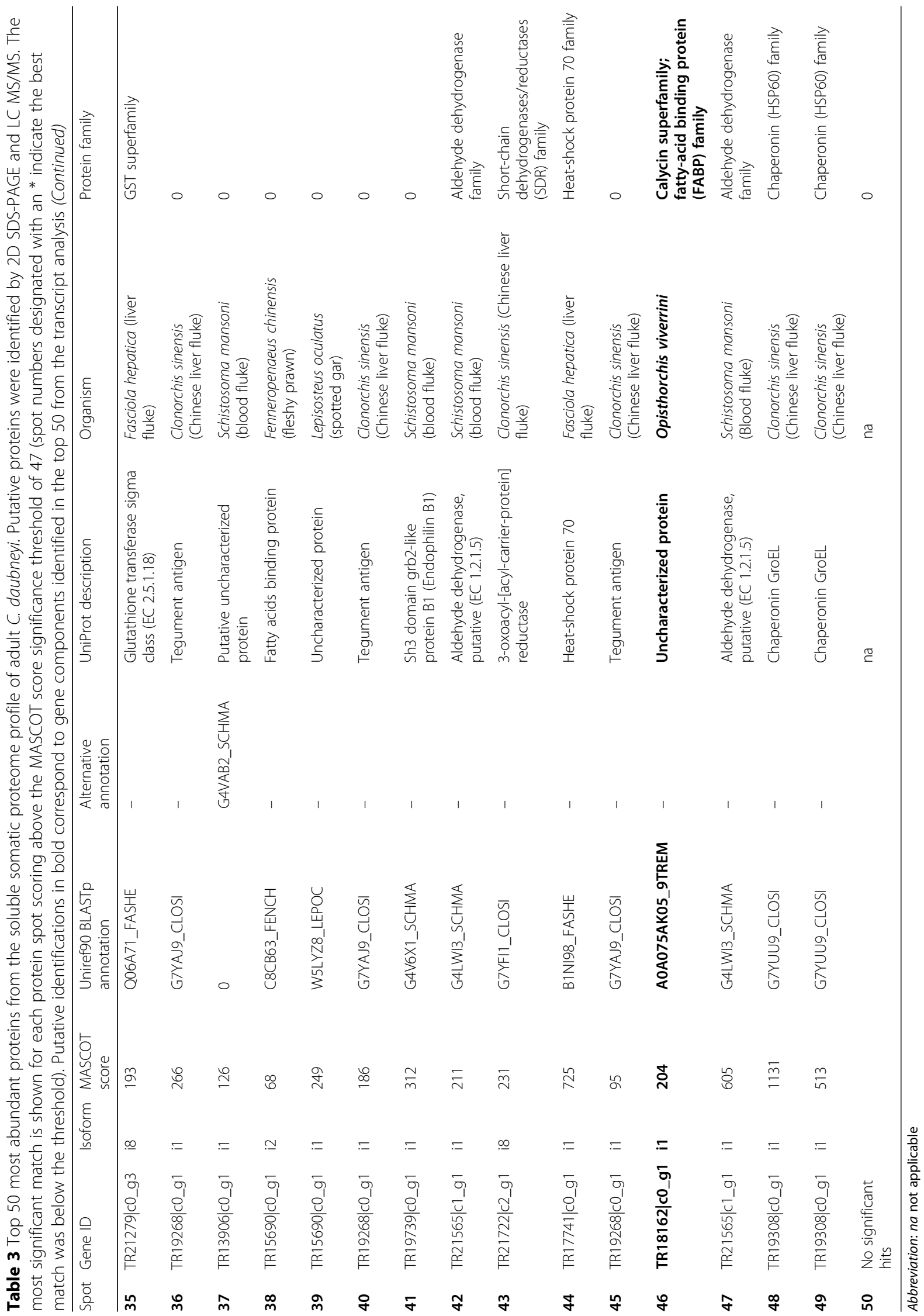




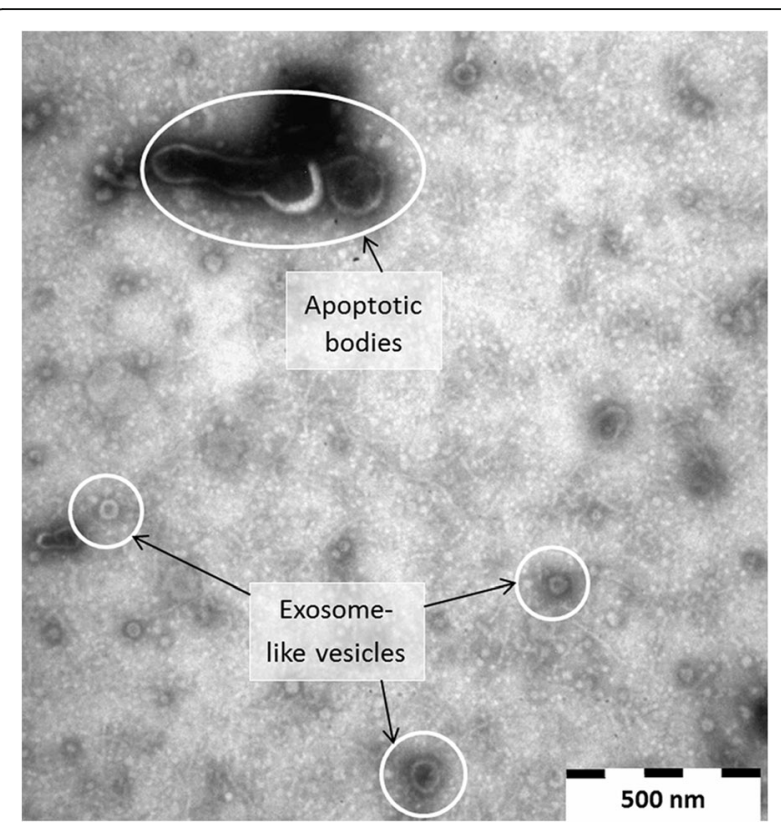

Fig. 4 Extracellular (including exosome-like) vesicles (EVs) isolated from adult C. daubneyi excretory/secretory (ES). ES products were produced during in vitro culture and EVs identified using transmission electron microscopy. Preliminary vesicle characterisation (exosome-like and apoptotic bodies) are based on approximate size only

concentrations (tVFAs), acetate, propionate and others. Butyrate was seen to be significantly different between group 3 (silage and rumen fluke) and both group 2 (fluke only) and group 1 (blank culture) bottles but not different to the silage only group (group 4). In addition, no significant difference was observed between the silage only (group 4) and blank culture groups (group 1) at 6 h. At $24 \mathrm{~h}$, the same effect of silage treatment was evident, with significant differences between silage-positive and -negative groups for acetate, butyrate and other VFAs (Table 4). For the measurement of total VFAs a significantly higher concentration was seen in the silage and rumen fluke group (group 3) vs the silage only group (group 4) and both of these treatment groups compared to the silage negative bottles. This appears to be attributed to the significantly higher concentration of propionate detected in the fluke treated bottles $v s$ their respective controls at $24 \mathrm{~h}$. Analysis of the VFA profiles within each culture group revealed a significant increase in propionate in response to the presence of rumen fluke in both the silage positive and silage negative culture groups at $24 \mathrm{~h}$. At $6 \mathrm{~h}$, slightly higher propionate concentrations were recorded in the fluke treated groups in comparison to their respective silage/blank controls also but this was not statistically significant. Total VFA concentration was observed to be higher in the fluke only groups compared to the blank group, but again this was not significant in the measurement of total VFAs.
Bioinformatic analysis supported rumen fluke propionate metabolism as a number of key genes present in the $C$. daubneyi transcriptome are involved in propionate production (Fig. 5).

\section{Discussion}

The present study produced a transcriptome assembly that supported our first (and subsequent) global proteomic profiles of the ES and soluble somatic proteins of the rumen fluke $C$. daubneyi. In addition, this study shows for the first time that the presence of rumen fluke parasites impacts upon VFA production profiles in a rumen in vitro culture and may therefore impact on rumen fermentation kinetics in the host.

During transcriptomic analysis, signal peptides were predicted for $1.8 \%$ of mapped contigs, which is $2-3$ fold lower than has previously been observed in other trematodes; with $4.1 \%$ of predicted proteins containing an signal peptide in an Fascioloides magna transcriptome [17] and $5.1 \%$ in an Fasciola gigantica transcriptome [46]. However, both Cantacessi et al. [17] and Young et al. [46] describe transcriptomes which, whilst also produced by de novo assembly, were sequenced on an Illumina Genome Analyzer II platform with the resulting assembly performed using alternative bioinformatics software tools; Oases and SOAPdenovo respectively. In addition, both transcriptomes also reported fewer numbers of unique contigs and mapped reads than currently described for $C$. daubneyi, highlighting that notable differences are often obtained with different sequencing and data analysis approaches which can make direct comparisons problematic [47]. Therefore, future genome-guided assemblies may allow for more accurate comparisons to be completed. Of note is the absence of an analysis regarding the contigs containing a signal peptide within the P. cervi transcriptome by Choudhary et al. [25].

Secreted proteins (as indicated by a signal peptide) are thought to play a crucial role in the biology of parasitic helminths [48] and particularly in host-parasite interactions [49]. Thus, although classical signal peptide based secreted proteins are of lower abundance in the $C$. daubneyi transcriptome, they were present in several highly expressed sequences, i.e. 12 of the 50 most expressed gene components contained a predicted signal peptide. In addition, rumen fluke may utilise non-classical communication host interaction pathways such as carrying proteins as cargo of extracellular vesicles [38] and to this end many previously associated EV proteins were identified in the $C$. daubneyi ES preparation.

Overall, the $C$. daubneyi ES proteome was similar to related fluke species including F. magna [17] and F. hepatica $[32,50]$, with FABPs, proteases and peptidase proteins, including cathepsins, present. Proteins belonging to the GST superfamily have been well studied in other 


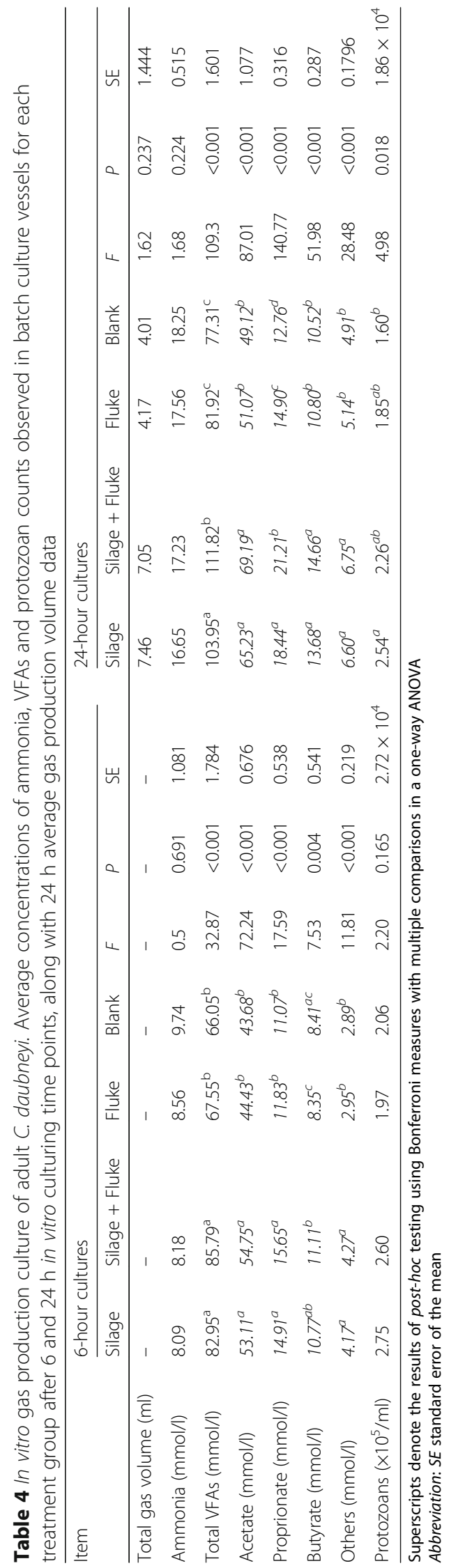




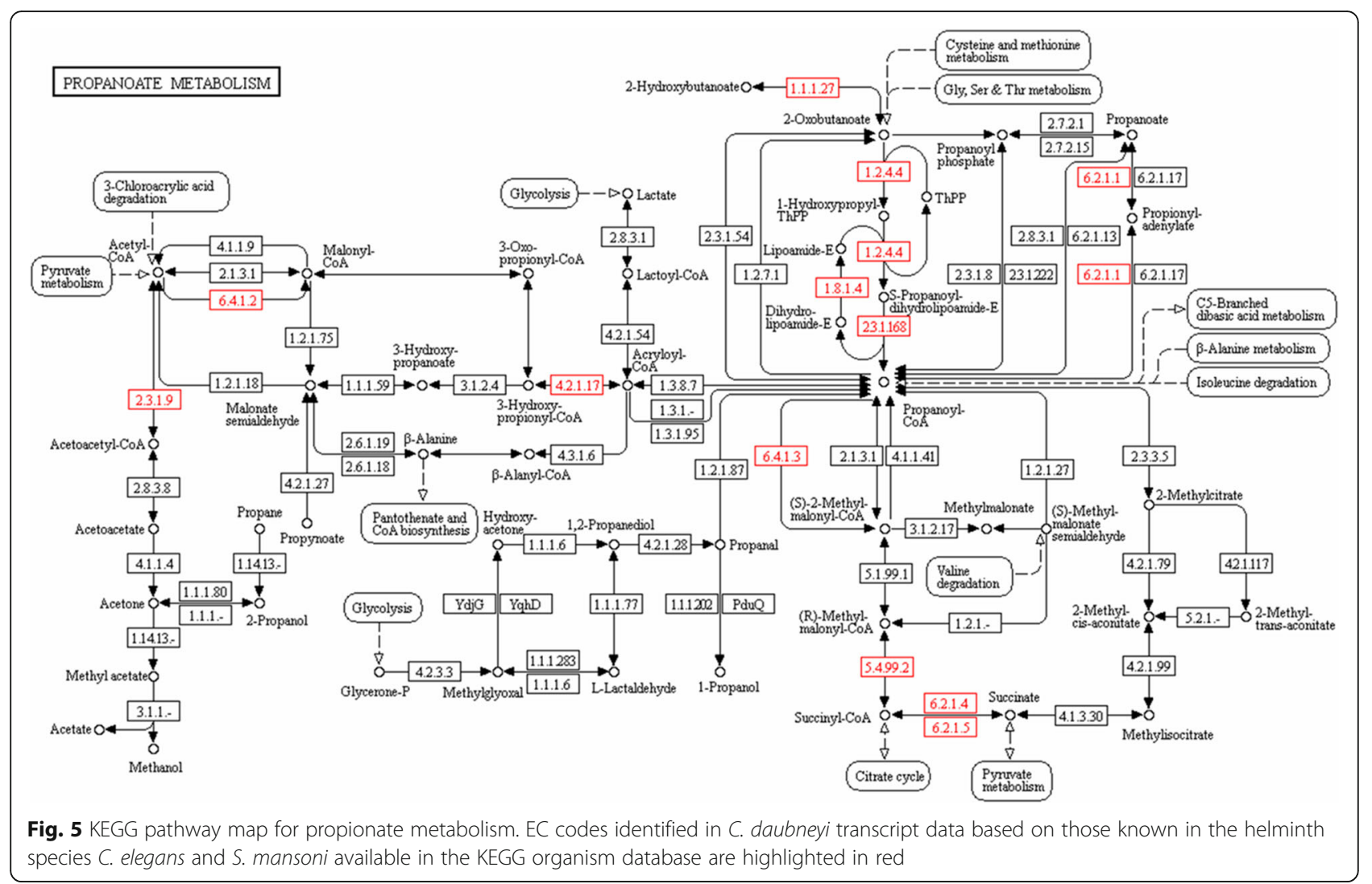

helminths and are of interest for their role in drug detoxification and as potential vaccine candidates, as they are known to be immunogenic and immune modulators $[51,52]$, so the identification of these proteins in $C$. daubneyi is interesting for future studies. The GST profile identified in $C$. daubneyi appears to mirror that of fasciolids [28] with the identification of one zeta class and two omega class GSTs. Therefore, the presence of a zeta class GST in C. daubneyi no longer makes Fasciola unique as suggested previously [27]. Of significant interest is the apparent expansion of the sigma class GST protein family with multiple sequences identified in $C$. daubneyi compared to significantly fewer in the fasciolid liver flukes $[28,53]$. It is likely that GSTs are present in the ES due to secretion via EVs as demonstrated for $F$. hepatica [37] and therefore this expansion of Sigma-like GSTs may be more related to host and regulation and regulation of the rumen environment rather than xenobiotic detoxification.

Additional detoxification proteins, namely CYP450s, were also identified in the $C$. daubneyi transcriptome but, as expected, were not represented in the abundant proteome. The expression of a single monooxygenase and one reductase mirrors $F$. hepatica [27] and the absence from a proteomic studies, including those incorporating membrane proteomics, has also been noted in other helminths [54]. However, it still remains likely that
CYP450s play an important role in fluke biology and xenobiotic detoxification.

Many of the 50 most abundant proteins identified by LC MS/MS in both the ES and somatic profiles are described as uncharacterised, although the majority of hits achieved were to proteins found in other fluke species or invertebrate animals. In contrast to the published ES 2DE proteome of $F$. hepatica [50], the profile observed for adult $C$. daubneyi parasites is not dominated by a few major proteins, but has numerous proteins present across a wide $\mathrm{pH}$ and $\mathrm{MW}$ range. A diverse profile of ES proteins is likely related to feeding, interaction and communication with the diverse niche of the rumen inhabited by adult rumen fluke.

With the complex nature of the rumen environment the decision to capture transcripts immediately ex-host opens the dataset to contamination from associated rumen eukaryotic microbes or plant tissue which was not removed during the wash process described. It is also noted that protozoan organisms have previously been observed within the oesophagus of rumen fluke parasites examined under SEM [55]. However, only 2 contigs in our dataset were found to have a best match to bovine sequences indicating a likely host contamination, but with only 2 such hits from over $73 \mathrm{~K}$ contigs this suggests host contamination is minimal. Bacterial sequences should have been largely excluded from our 
sequencing effort by the poly-A enrichment step during sequencing library preparation as mRNA from eukaryotic organisms is poly-adenylated to add stability whereas polyadenylation in prokaryotes is minimal in length and rapidly degraded [56]. However, it cannot be excluded that some erroneous protozoan, fungal and plant sequences are present in the dataset. That being said, a significant proportion of the most highly expressed sequences align to other trematode parasites.

This new rumen fluke data may have a role in developing future diagnostics as it identified both genes potentially unique to $C$. daubneyi, or to paramphistome species, and novel proteins in the ES profile which are likely to be host-exposed and potentially antigenic. This potential biomarker panel could be tested for the potential to detect paramphistome-specific DNA or protein signatures in faecal samples or antigen/antibody detection in either faecal or blood based ELISA tests such as those which have been developed for F. hepatica infections [57, 58].

During the life-cycle of $C$. daubneyi in the definitive host, described by Devos et al. [59], it is not yet clear how long a mature infection potentially persists. Moreover, different hypotheses have been formulated for how rumen fluke parasites feed in the host. Choudhary et al. [25] suggested that rumen flukes may survive by absorbing blood glucose from the host at the site of attachment to the rumen wall, but given the superficial nature of the attachment of their acetabulum, with the oral sucker exposed to the rumen contents this is thought unlikely. However, the present gas production experiment successfully culturing rumen fluke for $24 \mathrm{~h}$ ex-host in a rumen fluid-buffer mix provides evidence that rumen fluke are likely to prey on the rumen microbial community and/or obtain their nutrition from the products of microbial fermentation occurring in the rumen or the abundant plant material present as digesta, although this requires further investigation. The high abundance of uncharacterised FABPs in each proteome profile (both ES and somatic), with high levels of transcription also seen, suggests that fatty acids are of significant importance in paramphistome biology. The rumen appears a highly appropriate niche for these parasites to select, as it is known that many trematodes cannot synthesise their own fatty acid complement $[60,61]$. Such an environment is likely to have driven the expansion of the FABPs in C. daubneyi. This is especially so given that this expansion is driven in the designated CdFABP IL groups 1 and 2. Both of these FABP groups clustered with the vertebrate ileal and liver FABPs. Vertebrate ileal and liver FABPs are noted for their ability to bind fatty acids and bulky ligands such as cholesterol. Therefore, with the levels of fatty acids and cholesterol esters found within the rumen [62] that these groups of $C$. daubneyi FABPs have expanded to exploit this niche.
Understanding the impact of rumen fluke on the host is crucial. Thus, the present study utilised an in vitro experiment to understand rumen dynamics. Interestingly, no differences in protozoan numbers were observed despite the suggestion of predation on protozoans by adult rumen flukes. The only significant difference detected in this gas production experiment was an increase in propionate and total VFA production. It has been established that several nematode, cestode and trematode species actively produce propionate as an end product of their metabolism via the malate dismutation pathway, including succinate decarboxylation under anaerobic conditions, and that the presence or absence of oxygen appears to have no effect on their survival and ability to metabolise energy $[63,64]$. In the malate dismutation pathway, redox balance is maintained when twice as much succinate as acetate is formed, with succinate then being further converted to propionate by a decarboxylation reaction [65], with acetate and propionate the main excretory products produced by adult $F$. hepatica metabolism.

Given the increase in rumen fluke cultures of propionate levels it is likely that there may be a shift in the resulting microbial population. Thus, it is beneficial to confirm the source of propionate. Bioinformatics analysis here supports the hypothesis that the higher propionate levels detected over a 24-h in vitro rumen fermentation experiment in vessels with the addition of rumen fluke parasites is likely due to the production of propionate via rumen fluke metabolic activity. A number of key genes involved in the succinate decarboxylation pathway, and evidence of a complete pathway to propionate via genes involved in valine, leucine and isoleucine degradation (EC 1.2.4.4, 1.8.1.4 and 23.1.168 in Fig. 5) were identified in the $C$. daubneyi transcript data, with evidence of active gene expression from samples captured directly from the natural rumen environment.

However, although the greater levels of VFAs measured, and specifically propionate, will contribute to host nutrition, the ratio and concentration of rumen VFAs is also an important factor in the development of rumen acidosis. Where propionate levels increase and the acetate: propionate ratio decreases it is known that acidotic conditions in the rumen may occur. This is generally linked to levels of fibre $v s$ starch based feeds in the diet [66], but in animals where the diet fed creates higher levels of propionate in the rumen with $\mathrm{pH}$ conditions bordering acidosis, any additional production of propionate linked to the presence of rumen fluke could be an important factor to consider where acidosis then occurs. Lower acetate: propionate ratios are also linked to decreases in methane emissions from the rumen [67], which is important given methane emissions are a significant source of energy loss in ruminant systems, and also an important greenhouse gas [68]. 
Results of an abattoir study [69] identified significantly lower carcass cold weight and fat coverage measurements for rumen fluke infected beef cattle in comparison to their helminth-free counterparts, indicating a potential interaction between rumen fluke infections in temperate climates with $C$. daubneyi and measures of animal production. Additionally, with evidence of inflammatory reactions and atrophy of the rumen papillae previously identified in association with C. daubneyi infection [70], the effects of chronic tissue inflammation on the host animal associated with heavy and prolonged rumen fluke burdens, and atrophy of the rumen papillae and any potential for reducing the surface area available for nutrient uptake is unknown.

\section{Conclusions}

The present study provided a discovery platform (transcriptome, proteomes, EV isolation pipeline and in vitro fermentation system) to study the $C$. daubneyi host-interaction. This work has highlighted the FABPs as key players in survival within the rumen environment. Furthermore, the impact of adult fluke on rumen functionality has been demonstrated with reduced acetate: propionate ratio suggesting that acidotic conditions may occur within the rumen. However, further investigation into how the presence of rumen fluke infections may impact on animal health and production measures in temperate climates is clearly needed.

\section{Additional files}

Additional file 1: Full polyomic data. Table S1. Top C. daubneyi transcriptomic hits. Table S2. The full C. daubneyi transcriptomic hits. Table S3. BLAST searches of $C$. daubneyi transcripts against $P$. cervi. BLAST searches of $C$. daubneyi transcripts. Table S4. The full analysis of putative protein identifications from the excretory/secretory proteome profile of adult C. daubneyi. Table S5. The full analysis of putative proteins identified from the soluble somatic proteome profile of adult C. daubneyi. (XLSX $12697 \mathrm{~kb}$ )

Additional file 2: Figure S1. Phylogenetic analysis of C. daubneyi fatty acid binding proteins. Neighbor-joining phylogenetic tree constructed using amino acid sequences through MEGA v 6.0 with 1000 bootstrapped support and a Poisson correction. All reported accession numbers are from Genbank. Where sequences were identified in silico, only gene product numbers are reported. (TIF $1007 \mathrm{~kb}$ )

\section{Abbreviations}

BLAST: Basic Local Alignment Search Tool; DMEM: Dulbecco's modified eagle medium; ES: Excretory/secretory; FABP: Fatty acid binding protein; FEC: Faecal egg count; FPKM: Fragments per kilobase of transcript per million mapped reads; GO: Gene ontology; GST: Glutathione transferase; MS/ MS: Tandem mass spectrometry; MWCO: Molecular weight cut-off; PTMs: Post-translational modifications; TEM: Transmission electron microscopy; VFA: Volatile fatty acids

\section{Acknowledgements}

The authors are grateful to Randall Parker Foods (Wales) for providing C. daubneyi infected cattle and sheep rumen.

\section{Funding}

This work was supported by the Biotechnology and Biological Sciences Research Council (BBSRC) through strategic IBERS funding. In addition, AKS acknowledges specific support from the BBSRC (BBS/E/W/10964A-01; BBS/E/ W/0012843D)

\section{Availability of data and materials}

This Transcriptome Shotgun Assembly project has been deposited at DDBJ/ EMBL/GenBank under the accession GFUT00000000 and are available from https://www.ncbi.nlm.nih.gov/Traces/wgs/. The version described in this paper is the first version, GFUT01000000.

\section{Authors' contributions}

$\mathrm{KH}$ collected samples, performed all laboratory analyses and drafted the manuscript. DS, MH, KH, NA, RM, MV and MS performed bioinformatics analyses on the transcriptomics and proteomics data. HW, SG and EJ additionally performed gas production and in vitro culture analysis. HP performed mass spectrometry analysis. AKS, RM and PB supervised the work and completed and approved the final manuscript. All authors read and approved the final manuscript.

\section{Ethics approval}

Not applicable.

\section{Consent for publication}

Not applicable.

\section{Competing interests}

The authors declare that they have no competing interests.

\section{Publisher's Note}

Springer Nature remains neutral with regard to jurisdictional claims in published maps and institutional affiliations.

Received: 10 August 2018 Accepted: 20 November 2018

Published online: 04 December 2018

\section{References}

1. Charlier J, van der Voort M, Kenyon F, Skuce P, Vercruysse J. Chasing helminths and their economic impact on farmed ruminants. Trends Parasitol. 2014;30:361-7.

2. Charlier J, Velde FV, van der Voort M, Van Meensel J, Lauwers L, Cauberghe $\checkmark$, et al. ECONOHEALTH: Placing helminth infections of livestock in an economic and social context. Vet Parasitol. 2015;212:62-7.

3. Sanabria REF, Romero JR. Review and update of paramphistomosis. Helminthologia. 2008;45:64-8.

4. Pavan Kumar C, Syaama Sundar N, Devi Prasad V. Outbreak of immature paramphistomosis in Nellore Jodipi sheep. J Parasit Dis. 2016;40:533-5.

5. Jones RA, Williams HW, Dalesman S, Brophy PM. Confirmation of Galba truncatula as an intermediate host snail for Calicophoron daubneyi in Great Britain, with evidence of alternative snail species hosting Fasciola hepatica. Parasit Vectors. 2015:8:656.

6. Millar M, Colloff A, Scholes S. Disease associated with immature paramphistome infection. Vet Rec. 2012;171:509-10.

7. Tilling O. Rumen fluke in cattle in the UK: a review. Livestock. 2013;18:223-7.

8. Mason C, Stevenson H, Cox A, Dick I, Rodger C. Disease associated with immature paramphistome infection in sheep. Vet Rec. 2012:170:343-4.

9. Sargison N, Francis E, Davison C, Bronsvoort BMD, Handel I, Mazeri S. Observations on the biology, epidemiology and economic relevance of rumen flukes (Paramphistomidae) in cattle kept in a temperate environment. Vet Parasitol. 2016;219:7-16.

10. Gordon DK, Roberts LCP, Lean N, Zadoks RN, Sargison ND, Skuce PJ. Identification of the rumen fluke, Calicophoron daubneyi, in GB livestock: possible implications for liver fluke diagnosis. Vet Parasitol. 2013;195:65-71.

11. Willmott S. On the species of Paramphistomum Fischoeder, 1901 occurring in Britain and Ireland with notes on some material from the Netherlands and France. J Helminthol. 1950;24:155-70.

12. Huson KM, Oliver NAM, Robinson MW. Paramphistomosis of ruminants: an emerging parasitic disease in Europe. Trends Parasitol. 2017;33:836-44. 
13. Jones RA, Brophy PM, Mitchell ES, Williams HW. Rumen fluke (Calicophoron daubneyi) on Welsh farms: prevalence, risk factors and observations on coinfection with Fasciola hepatica. Parasitology. 2017;144:237-47.

14. Belanche A, Kingston-Smith AH, Newbold CJ. An integrated multi-omics approach reveals the effects of supplementing grass or grass hay with vitamin $E$ on the rumen microbiome and its function. Front Microbiol. 2016;7:905.

15. Huws SA, Mayorga OL, Theodorou MK, Onime LA, Kim EJ, Cookson AH, et al. Successional colonization of perennial ryegrass by rumen bacteria. Lett Appl Microbiol. 2013;56:186-96.

16. McDonald P, Edwards RA, Greenhalgh JFD, Morgan CA, Sinclair LA, Wilkinson TG. Animal Nutrition. 7th ed. London: Pearson; 2011.

17. Cantacessi C, Mulvenna J, Young ND, Kasny M, Horak P, Aziz A, et al. A deep exploration of the transcriptome and "excretory/secretory" proteome of adult Fascioloides magna. Mol Cell Proteomics. 2012;11:1340-53.

18. Neves BJ, Braga RC, Bezerra JCB, Cravo PVL, Andrade CH. In silico repositioning-chemogenomics strategy identifies new drugs with potential activity against multiple life stages of Schistosoma mansoni. Plos Neglect Trop Dis. 2015;9:e3435

19. Robinson MW, Menon R, Donnelly SM, Dalton JP, Ranganathan S. An integrated transcriptomics and proteomics analysis of the secretome of the helminth pathogen Fasciola hepatica: proteins associated with invasion and infection of the mammalian host. Mol Cell Proteomics. 2009; 8:1891-907.

20. Zhao J, Luo R, Xu XD, Zou Y, Zhang QF, Pan WQ. High-throughput sequencing of RNAs isolated by cross-linking immunoprecipitation (HITSCLIP) reveals Argonaute-associated microRNAs and targets in Schistosoma japonicum. Parasit Vectors. 2015:8:589.

21. Martinez-lbeas AM, Munita MP, Lawlor K, Sekiya M, Mulcahy G, Sayers R. Rumen fluke in Irish sheep: prevalence, risk factors and molecular identification of two paramphistome species. BMC Vet Res. 2016;12:143.

22. Bolger AM, Lohse M, Usadel B. Trimmomatic: a flexible trimmer for Illumina sequence data. Bioinformatics. 2014;30:2114-20.

23. Grabherr MG, Haas BJ, Yassour M, Levin JZ, Thompson DA, Amit I, et al. Fulllength transcriptome assembly from RNA-Seq data without a reference genome. Nat Biotechnol. 2011;29:644-52.

24. Li B, Dewey CN. RSEM: accurate transcript quantification from RNA-Seq data with or without a reference genome. BMC Bioinformatics. 2011;12:323.

25. Choudhary V, Garg S, Chourasia R, Hasnani JJ, Patel PV, Shah TM, et al. Transcriptome analysis of the adult rumen fluke Paramphistomum cervi following next generation sequencing. Gene. 2015;570:64-70.

26. Kanehisa M, Sato Y, Morishima K. BlastKOALA and GhostKOALA: KEGG Tools for functional characterization of genome and metagenome sequences. J Mol Biol. 2016:428:726-31.

27. Cwiklinski K, Dalton JP, Dufresne PJ, La Course J, Williams DJL, Hodgkinson J, et al. The Fasciola hepatica genome: gene duplication and polymorphism reveals adaptation to the host environment and the capacity for rapid evolution. Genome Biol. 2015;16:71.

28. Morphew RM, Eccleston N, Wilkinson TJ, McGarry J, Perally S, Prescott M, et al. Proteomics and In silico approaches to extend understanding of the glutathione transferase superfamily of the tropical liver fluke Fasciola gigantica. J Proteome Res. 2012;11:5876-89.

29. Morphew RM, Wilkinson TJ, Mackintosh N, Jahndel V, Paterson S, McVeigh P, et al. Exploring and expanding the fatty-acid-binding protein superfamily in Fasciola species. J Proteome Res. 2016;15:3308-21.

30. Hunter S, Jones P, Mitchell A, Apweiler R, Attwood TK, Bateman A, et al. InterPro in 2011: new developments in the family and domain prediction database. Nucleic Acids Res. 2012;40(Database issue):D306-12.

31. Buchan DWA, Minneci F, Nugent TCO, Bryson K, Jones DT. Scalable web services for the PSIPRED protein analysis workbench. Nucleic Acids Res. 2013;41:W349-W57.

32. Morphew RM, Wright HA, LaCourse EJ, Woods DJ, Brophy PM. Comparative proteomics of excretory-secretory proteins released by the liver fluke Fasciola hepatica in sheep host bile and during in vitro culture ex-host. Mol Cell Proteomics. 2007:6:963-72.

33. Bradford MM. Rapid and sensitive method for quantitation of microgram quantities of protein utilizing principle of protein dye binding. Anal Biochem. 1976;72:248-54.

34. Morphew RM, MacKintosh N, Hart EH, Prescott M, LaCourse EJ, Brophy PM. In vitro biomarker discovery in the parasitic flatworm Fasciola hepatica for monitoring chemotherapeutic treatment. EuPA Open Proteomics. 2014;3: 85-99.
35. Neuhoff V, Arold N, Taube D, Ehrhardt W. Improved staining of proteins in polyacrylamide gels including isoelectric focusing gels with clear background at nanogram sensitivity using Coomassie Brilliant Blue G-250 and R-250. Electrophoresis. 1988;9:255-62.

36. Buck AH, Coakley G, Simbari F, McSorley HJ, Quintana JF, Le Bihan T, et al. Exosomes secreted by nematode parasites transfer small RNAs to mammalian cells and modulate innate immunity. Nat Commun. 2014:5:5488.

37. Cwiklinski K, de la Torre-Escudero E, Trelis M, Bernal D, Dufresne PJ, Brennan GP, et al. The extracellular vesicles of the helminth pathogen, Fasciola hepatica: biogenesis pathways and cargo molecules involved in parasite pathogenesis. Mol Cell Proteomics. 2015;14:3258-73.

38. Marcilla A, Trelis M, Cortes A, Sotillo J, Cantalapiedra F, Minguez MT, et al. Extracellular vesicles from parasitic helminths contain specific excretory/ secretory proteins and are internalized in intestinal host cells. PloS One. 2012;7:e45974.

39. Nowacki FC, Swain MT, Klychnikov OI, Niazi U, Ivens A, Quintana JF, et al. Protein and small non-coding RNA-enriched extracellular vesicles are released by the pathogenic blood fluke Schistosoma mansoni. J Extracell Vesicles. 2015;4. https://doi.org/10.3402/jev.v4.28665.

40. Keerthikumar S, Chisanga D, Ariyaratne D, Saffar H, Anand S, Zhao KN, et al. ExoCarta: a web-based compendium of exosomal cargo. J Mol Biol. 2016; 428:688-92.

41. Owen RW, Coleman GS. The cultivation of the rumen ciliate Entodinium longinucleatum. J Appl Bacteriol. 1976;41:341-4.

42. Gonzalez-Warleta M, Lladosa S, Castro-Hermida JA, Martinez-lbeas AM, Conesa D, Munoz F, et al. Bovine paramphistomosis in Galicia (Spain): prevalence, intensity, aetiology and geospatial distribution of the infection. Vet Parasitol. 2013;191:252-63.

43. Chen XB. Neway Excel: A utility for processing data of feed degradability and in vitro gas production (version5.0). Rowett Research Institute: Aberdeen; 1997

44. Orskov ER, McDonald I. The estimation of protein degradability in the rumen from incubation measurements weighted according to rate of passage. J Agr Sci. 1979;92:499-503.

45. Hall TA. BioEdit: a user-friendly biological sequence alignment editor and analysis program for Windows 95/98/NT. Nucl Acids Symp Ser. 1999;41:95-8.

46. Young ND, Jex AR, Cantacessi C, Hall RS, Campbell BE, Spithill TW, et al. A portrait of the transcriptome of the neglected trematode, Fasciola gigantica - biological and biotechnological implications. Plos Neglect Trop D. 2011;5:e1004.

47. Steijger T, Abril JF, Engstrom PG, Kokocinski F, Hubbard TJ, Guigo R, et al. Assessment of transcript reconstruction methods for RNA-seq. Nat Methods. 2013;10:1177-84.

48. Gomez S, Adalid-Peralta L, Palafox-Fonseca H, Cantu-Robles VA, Soberon X, Sciutto $E$, et al. Genome analysis of excretory/secretory proteins in Taenia solium reveals their abundance of antigenic regions (AAR). Sci Rep. 2015:5:9683.

49. Sotillo J, Sanchez-Flores A, Cantacessi C, Harcus Y, Pickering D, Bouchery T, et al. Secreted proteomes of different developmental stages of the gastrointestinal nematode Nippostrongylus brasiliensis. Mol Cell Proteomics. 2014;13:2736-51.

50. Jefferies JR, Campbell AM, Van Rossum AJ, Barrett J, Brophy PM. Proteomic analysis of Fasciola hepatica excretory-secretory products. Proteomics. 2001; 1:1128-32.

51. Dowling DJ, Hamilton CM, Donnelly S, La Course J, Brophy PM, Dalton J, et al. Major secretory antigens of the helminth Fasciola hepatica activate a suppressive dendritic cell phenotype that attenuates Th17 cells but fails to activate Th2 immune responses. Infect Immun. 2010;78:793-801.

52. Perally S, LaCourse EJ, Campbell AM, Brophy PM. Heme transport and detoxification in nematodes: subproteomics evidence of differential role of glutathione transferases. J Proteome Res. 2008;7:4557-65.

53. LaCourse JE, Perally S, Morphew RM, Moxon JV, Prescott MC, Dowling D, et al. The sigma class glutathione transferase of the liver fluke Fasciola hepatica. Plos Neglect Trop Dis. 2012;6(5):e1666.

54. Brophy PM, Mackintosh N, Morphew RM. Anthelmintic metabolism in parasitic helminths: proteomic insights. Parasitology. 2012;139:1205-17.

55. Nikander S, Saari S. Notable seasonal variation observed in the morphology of the reindeer rumen fluke (Paramphistomum leydeni) in Finland. Rangifer. 2007;27:47-57.

56. Dreyfus $M$, Regnier P. The poly $(A)$ tail of mRNAs: bodyguard in eukaryotes, scavenger in bacteria. Cell. 2002;111:611-3. 
57. Mezo M, Gonzalez-Warleta M, Carro C, Ubeira FM. An ultrasensitive capture ELISA for detection of Fasciola hepatica coproantigens in sheep and cattle using a new monoclonal antibody (MM3). J Parasitol. 2004;90:845-52.

58. Salimi-Bejestani MR, McGarry JW, Felstead S, Ortiz P, Akca A, Williams DJL. Development of an antibody-detection ELISA for Fasciola hepatica and its evaluation against a commercially available test. Res Vet Sci. 2005;78:177-81.

59. Devos J, Vassiloglou B, Amenna-Bernard N, Marcotty T. Paramphistomosis in sheep; natural infection of lambs by Calicophoron daubneyi. Rev Med Vet. 2013;164:528-35.

60. Brouwers J, Smeenk IMB, vanGolde LMG, Tielens AGM. The incorporation, modification and turnover of fatty acids in adult Schistosoma mansoni. Mol Biochem Parasitol. 1997;88:175-85.

61. Lee JS, Yong TS. Expression and cross-species reactivity of fatty acid-binding protein of Clonorchis sinensis. Parasitol Res. 2004;93:339-43.

62. Saleem F, Bouatra S, Guo AC, Psychogios N, Mandal R, Dunn SM, et al. The bovine ruminal fluid metabolome. Metabolomics. 2013;9:360-78.

63. Pietrzak SM, Saz HJ. Succinate decarboxylation to propionate and the associated phosphorylation in Fasciola hepatica and Spirometra mansonoides. Mol Biochem Parasitol. 1981;3:61-70.

64. Maule AG, Marks NJ. Parasitic Flatworms: Molecular Biology, Biochemistry, Immunology and Physiology. Wallingford: CABI Publishing; 2006.

65. van Grinsven KWA, van Hellemond JJ, Tielens AGM. Acetate: succinate CoAtransferase in the anaerobic mitochondria of Fasciola hepatica. Mol Biochem Parasitol. 2009;164:74-9.

66. Li S, Khafipour E, Krause DO, Kroeker A, Rodriguez-Lecompte JC, Gozho GN, et al. Effects of subacute ruminal acidosis challenges on fermentation and endotoxins in the rumen and hindgut of dairy cows. J Dairy Sci. 2012;95: 294-303.

67. Russell JB. The importance of $\mathrm{pH}$ in the regulation of ruminal acetate to propionate ratio and methane production in vitro. J Dairy Sci. 1998:81:3222-30.

68. Negussie E, de Haas Y, Dehareng F, Dewhurst RJ, Dijkstra J, Gengler N, et al. Large-scale indirect measurements for enteric methane emissions in dairy cattle: a review of proxies and their potential for use in management and breeding decisions. J Dairy Sci. 2017;100:2433-53.

69. Bellet C, Green MJ, Vickers M, Forbes A, Berry E, Kaler J. Ostertagia spp, rumen fluke and liver fluke single- and poly-infections in cattle: an abattoir study of prevalence and production impacts in England and Wales. Prev Vet Med. 2016;132:98-106.

70. Fuertes M, Perez V, Benavides J, Gonzalez-Lanza MC, Mezo M, GonzalezWarleta $\mathrm{M}$, et al. Pathological changes in cattle naturally infected by Calicophoron daubneyi adult flukes. Vet Parasitol. 2015;209:188-96.

Ready to submit your research? Choose BMC and benefit from:

- fast, convenient online submission

- thorough peer review by experienced researchers in your field

- rapid publication on acceptance

- support for research data, including large and complex data types

- gold Open Access which fosters wider collaboration and increased citations

- maximum visibility for your research: over $100 \mathrm{M}$ website views per year

At $\mathrm{BMC}$, research is always in progress.

Learn more biomedcentral.com/submissions 